\title{
THE EVOLUTION AND METHODS OF MANUFACTURE OF SPUR-GEARING.
}

By Mr. Thomas humpage, Member, of Bristol.

\section{Origin of Spor-Graring.}

The best authorities on the subject are unable to say when spur-gearing was first introduced, but it has certainly been used for an exceedingly long period. The following is a suggestion put forward by the author as to its origin. Fig. 1, Plate 21, shows two trunks of trees lying on the ground at right angles to each other, the stumps of the branches of one being interlocked with those of the other. When the branch is pressed down it causes the trunk to roll slightly on the ground, and the interlocked branches transmit the motion to the other trunk. Fig. 2 is a sketch which suggests the first piece of work made in the evolution of spur-gearing.

The first practical applications of spur-gearing to machinery were undoubtedly in connection with wind-mills and water-wheels for moving stones to grind corn. Fig. 3 is taken from an ancient drawing of a wind-mill in which the wheels and axles were made entirely of hard wood. The arms were fixed, high above the ground, to a horizontal shaft which transmits the motion through a pair of wheels to a vertical shaft, This vertical shaft drives the upper 
stone, and the weight of the stone combined with the circular motion crushes and grinds the corn.

From the earliest times waterfalls must have impressed the mind of man with the idea of utilising their force, and the outcome of this was the water-wheel. Fig. 4, Plate 21, is from an old drawing of a water-wheel. Spur-wheels were the only means of conveying the motion to the stones, belts and chains being unknown at that period.

For a great number of years all gearing of this kind was made of wood. Fig. 5 is taken from an old built-up wheel entirely made of hard wood. It is about 44 inches in diameter, having 55 teeth of $2 \frac{1}{2}$ inches pitch. The spurs are fitted into square holes in its periphery and pegged, the projecting parts being square.

The pinion is made up of two discs of oak. Through each disc nine holes were bored at equal distances round the correct pitch circle for nine teeth. Nine wooden bars of round section were fixed in the holes, and kept the two discs apart. These bars acted as teeth and geared with the large wheel. Similar pinions were very common in the old mills, and as they suggested the shape of a lantern, they were called "lantern" pinions.

In the old days nearly all millers built their own mills and kept them in repair. Later on some of these men found it to their advantage to give up milling and to devote their whole time to putting up mills and doing the necessary repairs, and these specialists were called millwrights.

The wooden spurs from continual use wore very badly and the millwright put in spurs with larger wearing faces, which gradually shaped each other, becoming hollow in the flank and rounded towards the points. When broken spurs were replaced, the curred shape was given to them so that they would work smoothly with the others, and when new wheels were put in they were fitted throughout with shaped spurs. This was the origin of the epicycloidal form of tooth. An old cider-mill in Herefordshire, which must be considerably more than a century old, has wheels of oak in which the spurs have been roughly shaped to an involute form. Iron spurs were once tried in place of the wooden spurs, but after a little work they became loose. The noise that they made was very objectionable, and eventually a return was made to wooden spurs. 
For heary work the millwright introduced an iron wheel with spurs on the rim, east in one piece. A wooden pattern of the whole wheel was made with the teeth shaped and spaced round the circumference as accurately as possible. Then, after the casting was made, the millwright had to piteh and trim every tooth with hammer and chisel, finishing them with a file or piece of grindingstone. To work with this wheel the millwright devised an iron wheel which, instead of having teeth cast on its periphery, had holes or mortices cored in the rim at equal distances apart. Into these mortices hard wooden teeth or cogs were fixed and the projecting parts were divided and shaped to gear smoothly with the cast-iron teeth. Many of these mortice wheels are working at the present day and are considered most suitable for their purpose. As time went on the wooden cogs gave trouble, for owing to shrinkage and the great pressures they became loose. Eventually another iron wheel with cast teeth took the place of the mortice wheel.

It was the common practice to have what was known as a hunting tooth in the large wheel, that is one tooth more or less than an exact ratio between the wheel and pinion. The object was to obtain a complete interchange of all the teeth so that they wore evenly and smoothly.

Clocks.- In the early part of the 13 th century a machine had been invented which the maker called a "time machine." It was a mass of spur-wheels, pinions and spindles, and was to supersede the sand-glass, water-clock, and sun-dial. This, which at first appeared to be an unimportant mechanical device, now beats time for the whole of the civilised world. In a book* called "Former Clock and Watch Makers," by F. G. Britten, we read of a clock which is said to have been made about the year 1335 by Peter Lightfoot, an ingenious monk of Glastonbury Abbey, for and at the expense of his superior, Adam-de-Sodbury, who was promoted to the Abbacy of Glastonbury in 1332. The old interior works of this elock were of iron, not differing materially in principle from the mechanism of much later date clocks, except that the appliances for the variety of the

* Published by E. and F. N. Spon, 125, Strand, Tondon. 
movements of the dial plate were necessarily complicated. After going for nearly five centuries, the works were found to be so completely worn out that about the year 1835 they were replaced by a new train; the old movement, now controlled by a pendulum, may be seen in action at the South Kensington Museum. Reference is also made in the same book to a water-clock with a rack and pinion, Fig. 6, Plate 21, which was used in Egypt about 300 в.c., so that it can safely be sail that spur-wheels have been in use for an exceedingly long period. The author has in his possession an ancient clock-wheel which is probably some centuries old. The diameter is about 10 inches, there being seventy-eight teeth of about $\frac{3}{8}$ inch pitch and $\frac{3}{8}$ inch thick. The whole wheel is made of wroughtiron. The rim was bent and welded together and shows clearly the scarfed joint. The four arms and the boss appear to have been forged ont of one piece, and the extremities of the arms are let into the rim for about $\frac{1}{4}$ inch and riveted over. A circle has been scribed on both sides for the whole depth of the teeth, and from this circle to the outside diameter division lines are scribed radially for each tooth. These division lines are much more accurately spaced than the teeth themselves, which vary eonsiderably. There is absolutely no trace of any machine work having been done on the wheel. It is generally believed that all clock-wheels made up to the end of the 15th century were of iron and made entirely by hand. Some time ruring the 16th century clock-wheels were made of brass, and a great change was made in the method of cutting the teeth.

\section{Wheed-Cutting Machinery.}

Fig. 7, Plate 22, is taken from a photograph of an old wheel-cutting machine which has almost certainly been in use for 150 years. The present owner, Mr. George Lewton, of Winterbourne, near Bristol, is 85 years of age and he still cuts wheels on it. It was used by his father and grandfather before him, and neither of these claimed to have made the machine. The machine is made of wrought-iron, with the exception of a few small parts which are of brass. The handle for working it is scen on the right- 
hand side of the machine. This handle turns a spindle provided with a brass wheel which gears into a small wheel on the arbor or cutter mandrel. On this arbor is fixed a circular saw of the exact thickness of the space required. The whole is carried on a hinged frame and kept up from the bed by a flat spring. The cutter is fed down through the blank by pressing down the handle seen on the left-hand side of the hinged frame. The bed proper of the machine is oblong in plan, having apparently been welded at each corner. Short legs are fixed to the under side of the bed, of sufficient length to protect the dividing plate, which is carried underneath a slotted bar extending the whole length of the frame. The dividing plate is fixed to an arbor or work mandrel, which is free to revolve in a bearing carried by the slotted bar, and it can be moved by a long screw to suit the diameter of the wheel to be cut. The dividing plate has a number of holes drilled in concentric circles, each eircle containing a different number of holes according to the number of teeth to be cut. The plate is fixed by a conical point carried on the ond of a long flat spring and dropping into the holes. From 100 to 200 teeth per hour can be cut in clock-wheels by this machine when worked by hand. No attempt was made to shape the teeth on the machine, the points being rounded off afterwards with a file. These teeth are exactly similar to those which were cut during the 16 th century.

Fig. 8 shows a wheel-cutting machine which may still be seen in use in Messrs. Dell and Co.'s Shop, Broad Street, Bristol. This marks a considerable advance over the machine just described, as the cutter is carried on a vertical slide. A foot treadle supplies the motive power, and the feed is put on by hand. This machine is about a century old.

Clock Pinions.-In all the old clocks the pinions were either made of wrought-iron or steel from the solid, or they were iron lantern pinions built up in the way already described in connection with old mills.

Cut Wheels for Patterns.--The speeds at which machines were driven had been increased from time to time, and better wheels were called for. Eventually the teeth of the patterns for small 
wheels were divided and cut in a machine similar to the clockmaker's engine. The teeth were epicycloidal and shaped entirely in the machine itself by formed cutters. From these metal patterns very good wheels were cast, and little labour was required to get them to run smoothly and quietly. For the better class of work, such as cotton spinning machinery, the wheels were cut from the solid, and these proved far superior in practice to cast wheels.

Wheel-Cutting Mrachine.-One of the first known makers of wheelcutting machines was J. G. Bodmer, a Swiss engineer, whose works were in Manchester. Fig. 9, Plate 22, is from a photo of wheels cut by his machine about 1820 to 1830 . The spur-wheel and pinion are patterns for the founder to mould from. They are of $\frac{1}{2}$ inch pitch and have 145 and 15 teeth respectively. The length of the teeth is the same as the pitch, and at first sight it appears impossible for them to gear, but when tried together they work very smoothly. These teeth were cut with a formed disc cutter. Fig. 12 shows one of its six segments which were apparently held together by a collar on each side, and fixed rigidly by a nut on the mandrel. The teeth of this segment were cut by a milling-cutter guided by a former, and the top portions were filed after milling. Cutters like this composed of segments were novelties, but the style of the teeth, copied from the rose-bit, was common. If these cutters were sharpened, the thickness of the teeth would be slightly increased, and the parallel portion which cuts the part below the pitch line would cut too narrow a space. Hence the cutters were not sharpened, and their life was very short.

Fig. 10 is taken from a photo of a wheel-cutting machine made between the years 1824 and 1834. A vertical frame carries at the back a dividing wheel and worm, and a set of change wheels is provided to give the divisions for any number of teeth required. The blank is carried on the front of the frame on a horizontal spindle, and the cutter is fed in horizontally by hand. An arrangement is also shown whereby the cutter-head can be tilted for cutting bevel-wheels. The method of driving the cutter was evidently by a gut-band passing over two jockey-pulleys, and as no gearing was used to help the band, only small pitches could be cut. 
In the middle of the cutter mandrel is seen a hole for a single pointed cutting tool or fly-cutter. The machine has all the essential points of an up-to-date Gould and Eberhardt machine, with the exception of the automatic feed and the end support for the mandrel. This machine together with others of the same type, but of larger capacities, are still working at an engineering works in Salford. The design is generally credited to Richard Roberts, a partner in the firm of Messrs. Sharp, Roberts and Co., of Manchester, but it is thought by others to be the work of J. G. Bodmer. After Bodmer had given up his works in Manchester he settled at Bolton, where he made another wheel-entting machine. This machine has a worktable 6 feet in diameter connected to a worm-wheel, 5 feet 4 inches in diameter, having 360 teeth of ${ }_{17}^{9}$ inch pitch. The accuracy of this worm-wheel at the present time leaves nothing to be desired. The cutter-head, carried on a pillar, is moved on the horizontal bed. according to the size of the wheel to be cut, and there was also an arrangement, not now available, whereby the cutter-head could be swivelled to any angle, for cutting bevel-wheels.

Involute teeth generated.--In 1835, Joseph Whitworth (afterwards Sir Joseph) was granted a patent for a wheel-cutting machine. From his specification it will be seen that the wheel blank being cut was a worm-wheel geared to the cutter by a train of wheels in an exact ratio and in such a manner that no slip could take place. In all probability, this was the first machine to generate involute teeth. Fig. 11 represents a machine made by Joseph Whitworth between the years 1834 and 1844, capable of cutting spur and bevel wheels. The main drive was by a gut-band and a pair of spur-wheels. The dividing was done by a large plate with holes drilled in circles and the cutter was fed by hand. Fig. 13, Plate 23, represents a much larger machine built by Whitworth for cutting spur-wheels only. In this the first drive is by a flat belt and then through a worm and wheel.

Machine for milling formed Cutters.-Fig. 14 shows a machine for milling the teeth in formed cutters. The former is nearly five times the dimensions of the cutter to be milled, so that any error in the shape of the former is reduced to one-fifth in the 
actual cutter. This machine was a great help to the tool-maker. It was no longer necessary to turn the blank to the exact shape, as the former would finish every tooth with the greatest accuracy. Bodmer probably used a machine of similar construction to this to produce his formed milling-cutters.

About the year 1851, Messrs. Shepherd, Hill and Spink made their first machine for cutting wheels. Fig. 15, Plate 23, is taken from a photograph of one of their earliest machines. The bed is long and narrow. The cutter bracket can be swivelled at its base for cutting bevel-wheels, and it is set to zero for cutting spur-wheels. The drive is by an endless rope and pair of spur-wheels to the cutter mandrel, and there is a self-acting feed. When one tooth is finished, the blank must be turned round by hand to the next, and the correct division is obtained by means of change-wheels. The dividing head and work mandrel are moved along the bed by a horizontal screw to suit the diameter of the wheel being cut.

Amongst J. G. Bodmer's many inventions was the "railway car solid tyre rolling mill" which gave the name to the Salford Rolling Mills. The owner of these mills, Mr. P. R. Jackson, took out a patent for a machine to mould the teeth of spur-wheels. Fig. 16, Plate 23, is from a photo of the earliest working machine made. A pattern is made forming a space between two teeth of the required wheel. This pattern is fixed to a vertical slide carried on the main bracket which can be moved along the bed by means of a rack and pinion to suit the diameter of the wheel to be moulded. The slide is lowered vertically until the pattern touches the surface of a sand bed contained in a circular moulding-box. This box is carried on a table which can be revolved by a worm and wheel, driven by suitable change-gears for the number of teeth required. The moulder rams sand into the space, thus forming the sides of two teeth, and the pattern is then lifted vertically out of the sand. The dividing handle is given one or more turns and this moves the table round through one space. The process is repeated until all the teeth are completed. At first the pattern teeth were made by hand, but soon afterwards these teeth as well as the teeth of mortice wheels were cut by machines specially brilt for the purpose. The first machine-moulded 
wheels ever made were shown by P. R. Jackson at the Great Exhibition of 1851 in London.

In 1856, Christian Schiele, of Oldham, took out a patent for a thread milling machine which was also capable of cutting the teeth of wheels. From his specification it is seen that the blank to be cut is geared up with the worm cutter, and when this cutter is efficiently guided the teeth will be perpendicular as in an ordinary spur-wheel. This marks a step in advance of Sir Joseph Whitworth's device already referred to, for Sir Joseph Whitworth's machine was only for cutting such wheels as have their teeth oblique to the axis. In Schiele's patent is undoubtedly the germ of the modern gear-hobbing machine, but the author has been unable to find any trace of such a machine having been made from this specification.

Fig. 17 (page 660) is a reproduction from an old drawing of the first gear-shaping machine designed by Mr. Potts, a member of the celebrated clock-making firm. It is described on the original drawing as "Potts' Patent Wheel cutting and dividing engine for cutting the teeth of bevel and spur gearing mathematically correct. Manufactured by Shepherd, Hill and Co., Leeds." This machine appears to be the first attempt at planning or shaping bevel and spur gear-wheels from a large former plate. A gold medal was awarded for this machine at the Paris Exhibition of 1867.

Fig. 18 (page 661) and Fig. 19, Plate 24, are taken from a book which illustrates all the important wheel-cutting machines exhibited at the Paris Exhibition of 1867, and their main features can easily be understood from the figures. There are no makers' names on these machines.

Machine Relieved Cutters.-It has already been seen that the early formed milling cutters were a very expensive item, owing to the fact that it was impossible to sharpen them without spoiling them. This gradually brought about the introduction of a new kind of eutter, now known as the relieved or backed-off cutter, which could be easily sharpened without altering its form. These relieved cutters have about one-fifth the number of teeth of one of the old formed cutters of the same size. The teeth are cut through from side to side, like a saw, for the whole depth of the formed part, and the 

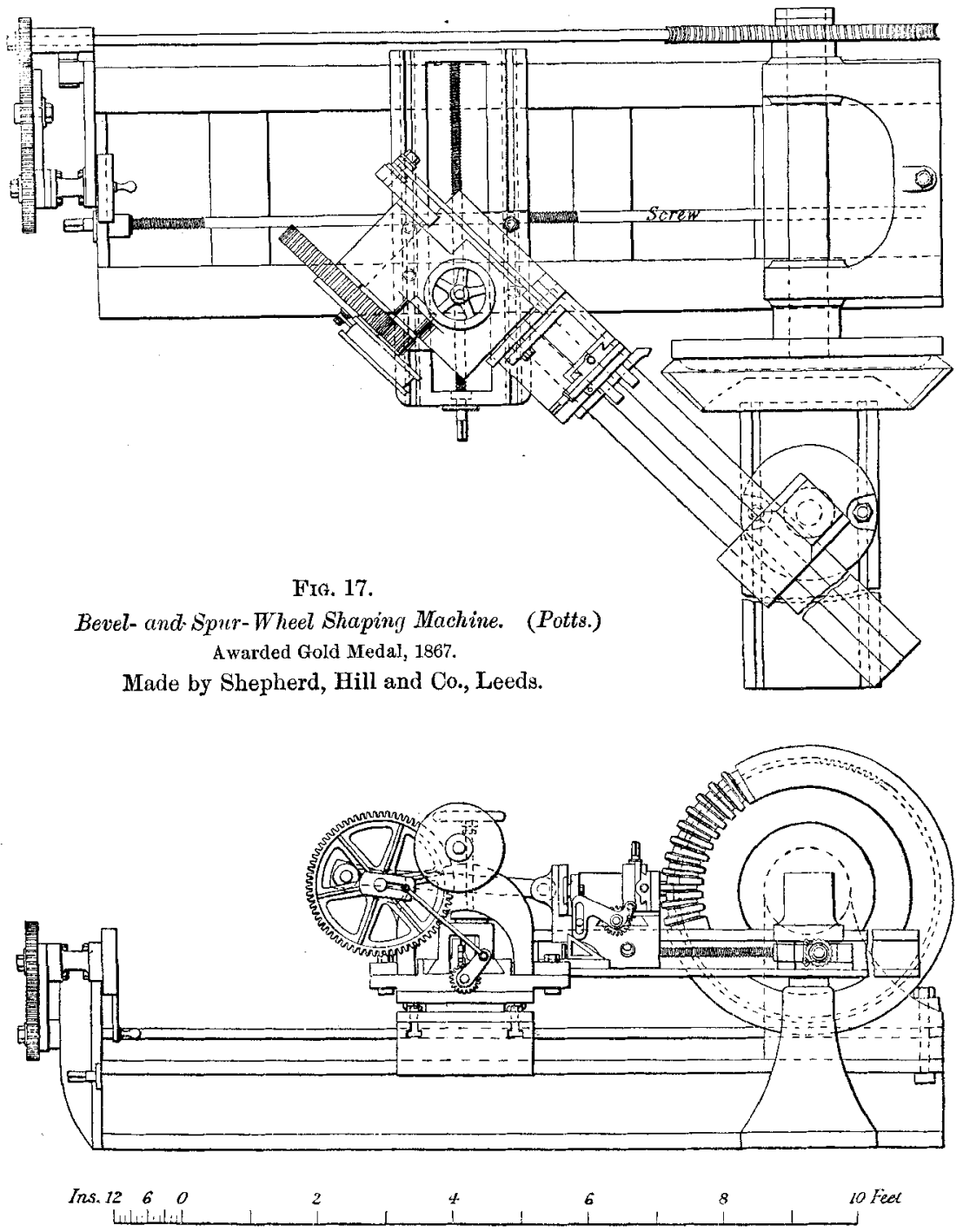
cutting face is radial. The backing-off to the tecth was done on a slotting or shaping machine with a formed tool. Fig. 20, Plate 24, shows a cutter made in this way. At this time the great majority of spur-wheel teeth for engineers were of the epicycloidal form. These teeth were difficult to cut even with a relieved milling cutter, owing to the flanks of the teeth being nearly parallel. After a little use the cutters jammed in the work and so caused endless trouble. Yet with all this the milling cutter had proved very useful, and it was

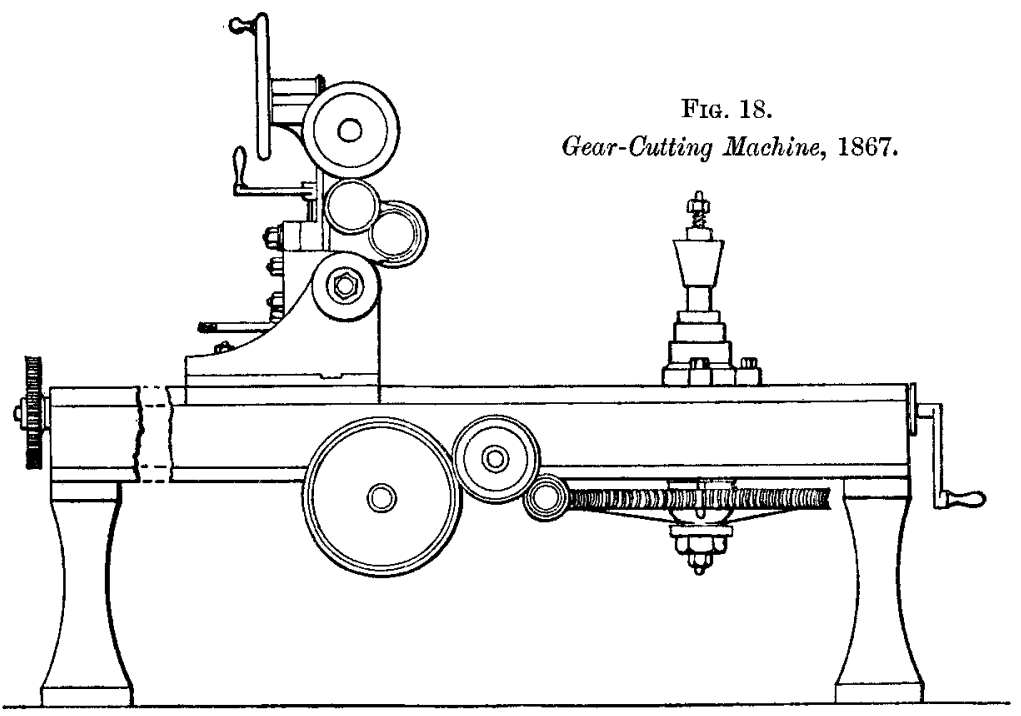

not long before an alteration in the shape of spur-teeth was made for small wheels.

Involute Cutters.-About the year 1874 Messrs. Brown and Sharpe, U.S.A., brought ont complete sets of machine relieved involute gear-cutters. The shape of the cutters was based upon a system first introduced by Professor Willis, of Cambridge, in 1836. In his book on forming the teeth of gear-wheels he recommended that the obliquity of the line of pressure should be made $14 \frac{1}{2}$ degrees. The suggestion was afterwards put into practice by Messrs. Brown and Sharpe, and cutters made on this system have been used in their 
own works since 1851. It was necessary that the roots of the teeth should be strong, and at the same time there must not be too great an outward thrust on the bearings. An angle of about 14 degrees to 16 degrees was considered to be the most suitable for meeting both these requirements. It was essential to adopt some uniform method, and a very simple construction was found by which an angle of $14 \frac{1}{2}$ degrees could easily be set out. The way in which Messrs. Brown and Sharpe arrived at the shape of the cutters was somewhat as follows. A rack with teeth having straight sides inclined to each other at an angle of 29 degrees formed the basis of the whole system. It was decided that twelve teeth in a pinion was the smallest practical number that could be used. The teeth were drawn of the correct involute form, but to allow the pinion to roll into the rack it was found that the flanks had to be very considerably undercut. This would have made the teeth weak, and it would have been difficnlt to mill out the spaces. On this account, it was determined to make the flanks radial, so giving the necessary clearance and enabling a disc millingcutter to be used. In American practice involute teeth are invariably employed, but in this country whilst all teeth of small pitch are involute, epicycloidal teeth are often used for the larger pitches. The great advantage of involute teeth is that the distance apart of the centres can be varied without impairing the efficiency of the gearing, and the angular velocity ratio remains constant. With epicycloidal teeth, on the other hand, the wheels must be kept exactly in gear on their correct centres or the teeth will wear very badly. With epicycloidal teeth the outward thrust is less than with involute teeth.

In 1877 or 1878 Messrs. Gould and Eberhardt, U.S.A., brought out an automatic gear-cutting machine. One of these machines was bought by Messrs. John Lang and Sons, Johnstone, about the year 1881 for eutting the wheels of their lathes, and this firm also made arrangements with the makers to act as their agents in Europe.

Double Helical Spur-gearing.-A About the year 1880 Messrs. P. R. Jackson and Co. brought out the double-helical spur-gearing, the object being to bring the teeth into gear more gradually, thereby 
reducing the noise. The true action of the teeth can be best understood from the following explanation. Take two short screws, one right and the other left hand, both of the same diameter and pitch. If one thread is rolled into the other the screws are single helical wheels. If the driven wheel is retarded the screws tend to move endwise in the direction of their axes and in opposite directions. To balance this end-pressure, add another pair of screws similar to the first pair, fixing a right-hand and left-hand screw together on each spindle. The result is a double helical wheel. It will be readily seen that the resistance has a tendency to separate the pair of screws on one spindle, while it tends to press the pair on the other spindle closer together. In heavy gearing the bursting and compressing forces due to the wedge action would become very great, but they are actually reduced by using multiple threads. This alters the angle of the threads, so that the threads are more nearly parallel to the axis of the wheel, and the ends of the threads have more the appearance of ordinary spur teeth.

Another very practical way of explaining this system is to make forty-one metal dises about $\frac{1}{16}$ inch thick. Bore and turn them and then, stringing them on a mandrel, clamp them together and cut teeth on them jnst as if they were one solid blank. Then slack the nut of the mandrel and, beginning from the outside, turn each disc so that the teeth are slightly in advance of those on the one before it. When the twenty-first or middle disc has been reached the other discs must be turned in the reverse direction, so that the teeth are now slightly behind those on the preceding discs. Great care must be taken to turn each dise through exactly the same amount. It will now be seen that one half of the teeth form a stepped right-hand helix and the other half a stepped left-hand helix, and the forty-one discs clamped together in this position form a stepped double helical wheel. If the edges of the teeth in a stepped wheel were bevelled off they would form correct double helical teeth, and the action would be more gradual. Stepped wheels and racks were made in many cases where smooth working was required, and many examples are still to be found in old planing machines. Correct double helical gearing when made by experienced firms is very 
silent in action, and for heavy duty nothing has yet replaced it either in regard to strength, silence or cost. The largest gears in the world have been made on this system by Messrs. P. R. Jackson's moulding machine, capable of moulding wheels up to 30 feet in diameter by 36 inches width of face and 9 inches pitch. The form of tooth is epicycloidal. The wooden pattern teeth were cut on a special device attached to the machine.

Machinery was now advancing with very rapid strides. Gearcutting machines and sets of standard involute cutters were being imported from the United States in large quantities, and in spite of the prediction of engineers that this state of things could not last long, it has, however, lasted up to the present day. The machines sent over were lightly built and of soft material, but the workmanship was very good. One of the pioneer machines from America was the Brainard, a full automatic gear-cutting machine for either spur or bevel wheels. The main frame of the machine is of the same type as a milling machine. The self action for advancing the blank after each space has been cut and the automatic return motion of the disc cutter are extremely ingenious.

In this country Messrs. P. R. Jackson and Co. have made gear-cutting machines for their own use, capable of cutting spur gears in iron or steel up to 30 feet in diameter by 36 inches width of face and 9 inches pitch. Messrs. Darling and Sellers, of Keighley, build an automatic machine of the vertical type for cutting heavy gearing.

Spur-Gear Planing Machine.-Messrs. Glenson, of Rochester, U.S.A., have made machines for planing the teeth of spur gears up to 24 feet diameter by 24 inches face and 6 inches pitch. A former plate is used as in Potts' original system. The large pitch gears usually cut on these machines are generally cast with teeth sufficiently thick to allow for machining. This reduces the weight of the castings, saves the time otherwise spent in stocking out the teeth, and the teeth are freer from sponginess owing to there being less metal in the rim. Fig. 21, Plate 24, shows one of these machines capable of planing wheels up to 15 feet in diameter at the works 
of Messrs. David Brown and Sons, of Huddersfield, and similar machines are used by Messrs. Arnold Pochin and Brother, of Manchester.

Spur-Gear Shaper.-A machine which works on an entirely different principle is known as the Bilgram spur-gear generating shaper, and its action is similar to that of the well-known Bilgram bevel gear planer.

Gear-shaper-Another kind of spur-gear generating machine is the Fellows' gear-shaper. Its action is similar to that of a slotting machine, but instead of the ordinary slotting tool it carries a twelve-toothed pinion for its cutter. The teeth are of true involute form, hardened and ground up all over. The spindle carried in the reciprocating vertical slide is geared up by spur-wheels and changewheels to the work-table. The cutter is fed into the blank to the full depth of the teeth, and then, while the cutter is continuously reciprocating, the blank and cutter slowly revolve together at the exact ratio between the number of teeth in the cutter and the blank being cut. One revolution of the blank completes the operation. Only one cutter is required for all wheels of the same piteh, and the machine is equally suitable for spur-wheels and internal wheels.

Other steps in the development of wheel-cutting machinery are exemplified in the Sellers, the Thompson and Fitton, Birch's, Gibson's (worm and bevel wheel cutter), Smith and Coventry's, and the Oerlikon machines. Each of the methods above mentioned or described forms a link in the development of wheel-cutting machinery. Sometimes the process has been by some sort of planing action, the tool being guided by a former, sometimes the process has been done by shaping tools, and at other times by milling cutters in various ways.

\section{Hobbing MaOHINes.}

Principle.-In all machines that have beon described so far, one tooth must be finished before the next one is begun, but in the gear-hobbing machine the teeth are generated in circles, and they are all begun and finished practically simultaneously. The cutter or hob consists of a cylinder having wound round it a 
single right-hand thread. The thread has straight sides inclined to each other at an angle of 30 degrees. This thread is divider into teeth by spiral slots cut through it at right angles to the thread, and the tops, sides and bottoms of the teeth are backed off. The cutter is fed down through the blank, and the blank and cutter are geared together by change-wheels, so that they revolve at the correct ratio between the number of teeth to be cut and the thread of the bob. That is to say, for one revolution of the blank the hob must make as many revolutions as there are teeth to be cut. The action is the same as that of an endless rack which is moved along in gear with the wheel that is being out. It is clear that the pitch line of the rack must move at exactly the same rate as the pitch line of the wheel. All the metal which interferes with the rack teeth is romoved. Thus the teeth of the wheel are generated to the true involute form, and only one hob is required for all wheels of the same pitch.

In order to cut a correct spur-tooth, the axis of the hob must be tilted to the angle of spiral of the thread. Otherwise, as the cutter is fed downward, the spaces would be cut too wide. It is also necessary that one tooth should be set exactly on the centre line of the machine. This is the tooth which finishes the bottoms of all the teeth in the wheel. If no tooth in the hob is set exactly on the centre line, the wheel teeth will be cut slightly out of upright. The hobbing principle was first foreshadowed by Sir Joseph Whitworth's invention of 1835, and a hobbing machine was actually invented more than fifty jears ago by Christian Schiele, who has already been referred to.

Gear-Hobling Machines.-It is probable, howevor, that one of the first gear-hobbers actually made is a machine that has been working continuously since 1893 in the works of Messrs. George Juenpt and Sons, Croton Falls, New York. This machine is shown in Fig. 22, Plate 25. Fig. 25, Plate 26, represents a gear-hobbing machine which was brought out about 1894 by Messrs. Reinecker, of Chemnitz, Germany. This machine was made to cut spur-wheels, worm wheels, and spiral wheels. In both these machines the gear blank is carried on a horizontal mandrel and the hobbing cutter is 
fed horizontally. A later example of the same type is the Biernatzki. By far the greater number of gear-hobbers are now, however, of the vertical type, that is to say the wheel blank is hold on a vertical mandrel, and the cutter is fed vertically downwards.

The best known is the Pfauter. These machines are made in many sizes; the largest, capable of hobbing wheels up to 10 feet in diameter and one diametral pitch, is shown in Fig. 23, Plate 25. The main drive is from a countershaft and stepped cone pulley in the bed near the ground. From the first driving shaft the motion is taken off to change wheels at the back of the machine and to a vertical shaft, and from this vertical shaft the motion is conveyed to the hobbing cutter by bevel wheels and spurs. The hob bracket can be swivelled completely over, so that the hob can work at any angle. The arrangement for cutting spiral wheels is very ingenious. A differential gear is placed between the change wheels and the wormshaft which revolves the work-table. This differential gear can be set by means of suitable change wheels to advance or retard the worm-shaft by the exact amount required. Another set of change wheels is used for the feed.

The first British firm to enter the field with a gear-hobbing machine was Messrs. John Holroyd and Co., of Milnrow. Fig. 24, Plate 26, shows a machine by this firn capable of hobbing a wheel 10 feet in diameter by 14 inches face and one diametral pitch. It is very heavily built, weighing about 30 tons. The machine will cut spur, worm or spiral gears, and it is so arranged that taper hobs or single pointed cutters can be used for cutting worm wheels.

Messrs. Armstrong, Whitworth and Co. make a machine to hob wheels up to 6 feet in diameter. The special feature of this machine is that instead of the work-table sliding on the bed to suit the diameter of the wheel being cut, the vertical column which carries the hob bracket is adjustable on the bed. In Messrs. Wallwork's machine the cutter spindle is driven by a worm and wheol to give smooth running. The feed is through a gear-box giving three changes. The top of the work mandrel is supported by a bracket fixed to two vertieal columns carried by the base slide of the worktable. 
Fig. 26, Plate 26, represents a machine built by the author's firm for cutting spur and worm wheels. In this machine no countershaft is required, and as the driving pulley is fixed on the top of the column, the machine can be put down anywhere in the works and the belt received at any angle. It is also so arranged that a motor can be mounted on the top of the column. When belt-driven there is a light, loose pulley and a heavy fly-wheol, which is found to be an advantage owing to the intermittent cutting of the hob. The flywheel runs at a constant speed, and a gear-box, Fig. 27, Plate 27, and Fig. 28 (page 669), giving four changes of speed, is provided, so that a constant torque is always maintained from the belt to the hobbing cutter. The rate of feed can be altored while the machine is running. The feed-gear, Fig. 29, Plate 27, consists of two taper cones and a belt which can be shifted by means of a fork, moved by a screw. To obtain a wide range of feeds the difference given by the cones is multiplied by means of an epicyclic gear, and practically all the strain is taken off the belt. Thus any feed can be given from 5 to 130 thousandths inch per revolution of the blank being ent. The work mandrel is tied to the top of the vertical column by two cross-stay bars to prevent deflection and stiffen the blank whilst being cut. A section through the worm driving the worktable is shown in Fig. 30. The machine is very stiffly built, and is intended to cut steel wheels of large pitch.

Manufacture of Hobs.--The chief trouble of this system of generating gears lies in the manufacture of the hobs. The hob is made out of one solid piece of steel, which is bored and turned and the keyway cut. Then the thread is roughly milled out and also the spiral slots between the teeth. Next the teeth are relieved or backed off in a special lathe, and the lathe tool is carried in a rest which has a multiple motion. For every tooth, the tool is moved in and out by means of a cam, and at the same time it is fed forwards to follow the thread of the hob. During this process an allowanee can be made for expansion or contraction anticipated in the hardening of the hob. After the teeth have been rolieved, the hob goes into the tempering department. This is the most dreaded part of the process, for the work which has been done so carefully may 
32-inch Gial-Hobing Machine (Fig. 26, Plate 26).

Fig. 28.-Change-Speed Gear.

Scale $\frac{1}{6}$ th.

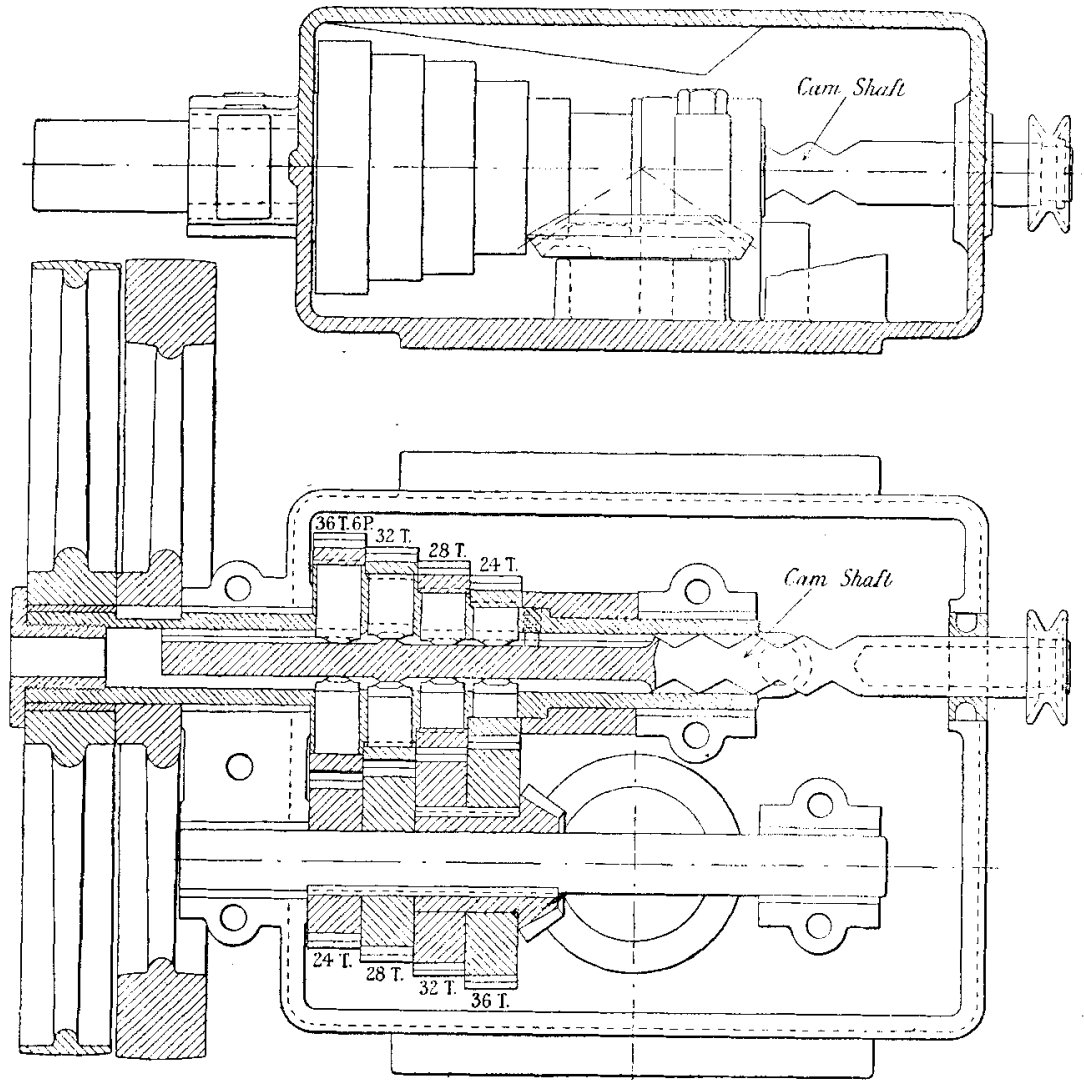

Fig. 30.-Worn driving the Wort-Table.

Scale $\frac{1}{6}$ th.

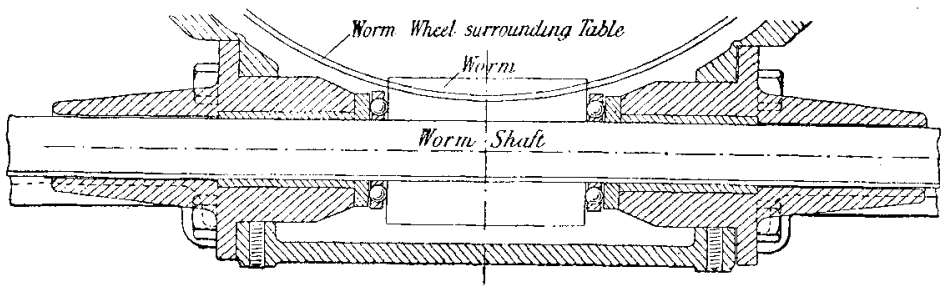


be spoilt in the fire or in cooling, even with the most experienced men. To complete the hob it is necessary to grind out the bore and over the tops of the teeth to true them up. Finally the cutting faces of the teeth are ground back just sufficiently to remove the grinding marks on the tops of the teeth.

Grinding Hobs.-Even after this lengthy process it is sometimes found that a hob has gone slightly out of pitch in the hardening. Attempts have been made to correct this by grinding the sides of the hob teeth after hardening. For this purpose a small emery wheel was used in the backing-off machine, but, owing to the small diameter of the emery wheel which had to be employed to pass between the threads and the great speed required, this has not proved very successful.

The author has brought out a hobbing cutter with inserted blades or racks which are fitted into grooves cut in the body of the hob. These grooves are not cut radially, for in a cross section of the hob the centre lines of the grooves are tangential to a small circle concentric with the periphery of the body. The thread is roughly cut and then the blades are taken out and tempered, and the parts that fit in the body are ground. They are then replaced in the body and the thread is ground up all over, so that any error due to tempering is corrected. The blades are again taken out of the body and turned end for end in the grooves, being replaced so as to keep the continuity of the thread. Owing to the grooves being tangential, this will tilt the blades and so give the necessary clearance or backing off to the teeth. The blades are rigidly held in the grooves of the body by long keys. Several sets of blades of different pitches either diametral or circular can be used in the same body, and if a tooth gets broken, it only means that one blade is spoilt, and this can easily be replaced. It is thought that this method of construction will lend itself particularly to hobs of large pitch, as at present the large solid hobs are very expensive. At the time of writing only two of these hobs have been made, and it is still too early to say how far they have an advantage over solid hobs. The results obtained are, however, sufficientily good to encourage further trials. 
Fig. 31.

Portions of five 12-tooth Pinions out on blanks sized for 11 teeth up to 13 teeth.

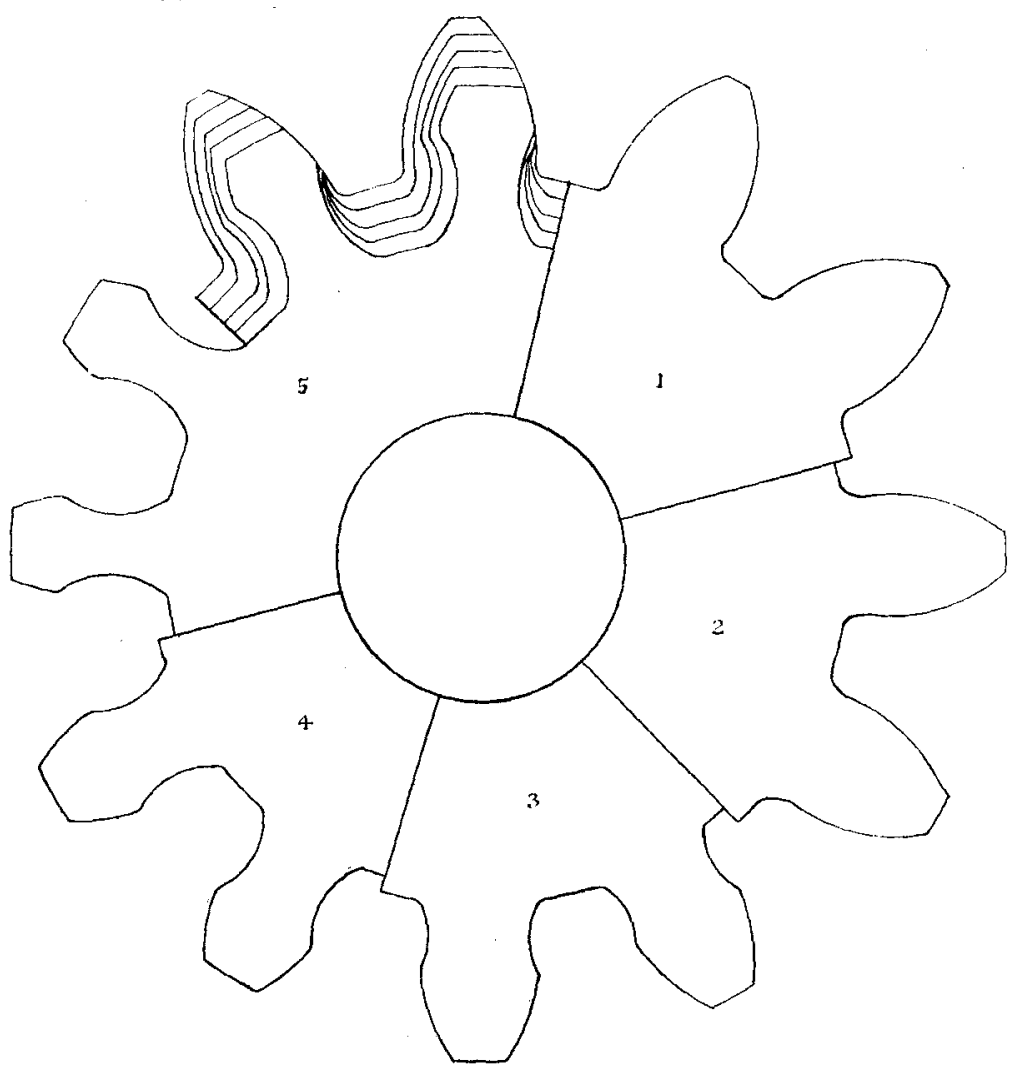


Undercutting of Pinions.-One point sometimes urged against the hobbing principle is that, as all the wheels are generated by rolling into a rack, the flanks of pinions must necessarily be undercut. The teeth of pinions could be made stronger by increasing the angle of the sides of the rack teeth, but this has the disadvantage of increasing the angle of obliquity and so throwing a greater outward thrust on the bearings. Nevertheless the evil effects of this increased angle of obliquity are thought by many to be exaggerated, and Wilfred Lewis recommends the use of involute teeth having an angle of obliquity of $22 \frac{1}{2}$ degrees.

The author is, however, in favour of retaining the present form of hob having sides inclined to each other at an angle of 30 degrees. In the case of wheels of less than thirty tecth, he recommends that the blank should be turned to a rather larger diameter than the correct diameter for the number of teeth required. The cutter is set to the full depth of the tooth just as if the blank were the correct size. The base circle, from which the involutes are unwound, is not altered by altering the size of the blank, but if the blank is over size we shall get teeth very strong in the roots with short flanks and long addenda. The centres of the wheel and pinion are, however, slightly further apart and the angle of obliquity is increased. Thus with the same hob, almost any desired strength can be given to the teeth of a pinion, and all the pinions will gear perfectly with the wheel cut on a correctly-sized blank.

It must be understood that there are limits to the amount of error which can be given to the diameter of the blank, for if the error is too great the teoth will be cut off altogether. As an illustration, take a 24-tooth wheol gearing into a 12-tooth pinion of 2 diametral pitch. The correct centres for these are 9 inches apart and the angle of obliquity is 15 degrees. Now cut twelve teeth on a blank intended for thirteon teeth. The centres will now be $9 \frac{1}{4}$ inches apart and the angle of obliquity is 21 degrees. This is rather an extreme case, but a very strong form of tooth can be obtained with a blank sized for $12 \frac{1}{2}$ teeth. The longer involute of the pinion teeth causes these wheels to run very smoothly together. Fig. 31 (page 671) illustrates a series of 12-tooth pinions cut on blanks sized for 11 teeth up to 
13 teeth. The third in the series is cut from a blank of the correct diameter.

Disadvantages of Disc Milling Cutters.-The introduction of automatic gear-cutting machines cheapened cut wheels to such an extent that they soon came into favour for all high-class work. As has been explained, unless the number of teeth to be cut in the blank correspond to the lowest number stamped on the cutter, the teeth will not be correctly shaped. Moreover, as the cutter gets blunt, the centres of the cutter and work mandrel are forced apart, and the bottoms of the teeth describe a slight scroll. Also as one tooth is finished at a time, the strains of the metal being released locally and the heat generated cause the wheel to be distorted from a true circle.

Disadvantages overcome by Hobbing Machines.-The extraordinary demands of modern high speed machinery rendered it necessary to find something still better. In all gear generating machines the teeth, no matter what number there are in the wheel, are developed to the true involute form so long as the tool keeps sharp, and in the gearhobbing machine, which generates the teeth simultaneously, nearly all the disadvantages of the disc milling cutter are overcome. Moreover, while the milling cutter has about twelve cutting teeth, in the case of a hob the cutting is done by about thirty teeth. In practice it is found that with a good stiff hobbing machine, from two to three times as much metal can be removed per hour as with a machine using a disc milling-cutter of the same pitch. With the improvements in hobs suggested by the author, the troubles caused by the hob going out of pitch in hardening may be eliminated, and wheels cut with such la hob as this probably come as near to perfection as can be obtained on any wheel-cutting machines.

Disadvantages of Hobbing principle.-Nevertheless, there are certain disadvantages of the hobbing principle. In the first place, owing to the spiral twist of the blades a section of the blade normal to the axis of the blank is not a perfectly true rack, and in consequence the points of the teeth being cut are very slightly too thick. Secondly, while the blank rotates continuously the cutting is 
intermittent, and after one tooth of the hob has taken a cut a small piece of metal escapes before the next tooth comes into action. If a hobbed wheel is examined it will be seen that the sides of the teeth show a series of small flats. By increasing the number of teeth in the hob, the flats are made smaller, and if there were an infinite number of teeth in the hob it would generate a smooth curve.

Grinding the Teeth of Wheels. - Of recent years there has been a great tendency towards grinding the teeth of the change gears for motor cars. At first the wheels were run in with emery and grease. This was found to take off as much metal from the parts that were correct as from those that were incorrect, and while some wheels ran much better after this treatment others were decidedly worse. However, something in the way of grinding has long been requisite, and about two years ago a machine was made by Messrs. Reinecker on the same principle as the machine used in the Fellows' gear-shaper system, for grinding the involute teeth of the eutters. The machine carries an emery wheel bevelled on each side to the shape of a racktooth with sides inclined at an angle of $29^{\circ}$. 'This wheel revolves at about 2,000 revolutions per minute. At the same time it moves bodily up and down through the space of tooth whilst the blank rolls under the restraint of two steel tapes, as in the Bilgram bevel gear planer. A few thousandths of an inch are left on the teeth for grinding, and the teeth are generated to the true involute form. One tooth is finished at a time, and then the blank automatically moves forward to the next space. The amount of wear on the emery wheel is said to be small, and the wheel can be trued up in its place. Gears ground by these machines show a great improvement over those which have not been ground. Nevertheless, owing to the gradual wear of the emery wheel there is a difference between the first and the last tooth finished in this way.

The author has devised a inachine for grinding the involute teeth of gear wheels, which works on the principle of the hobbing machine. The teeth are generated simultaneously so that distortion due to the heating of the blank is eliminated, and, as the downward feed of the abrasive wheel is very rapid, the wear is practically negligible. For purposes of experiment an ordinary 22-inch gear 
hobbing machine made by the author's firm was chosen. In place of the hob was substituted a cylinder of corundum, grit 50 and grade M, 10 inches in diameter and 7 inches long, having a continuous thread of 7 pitch cut upon it. The sides of the thread are straight and inclined at an angle of $30^{\circ}$, which is the exact shape of the thread of the hobbing cutter. The thickness of the thread on the pitch line is however made rather less than the correct thickness for a 7 pitch tooth. This corundum worm practically amounts to a hobbing cutter having an infinite number of teeth. The thread was roughed out in a lathe with Huntingdon dressers in seven hours, and finished by grinding on a Greenfield universal tool grinder with a carborundum wheel in twenty-one hours. It is thought that it may be possible to save much time in manufacture by moulding the thread roughly into shape. In place of driving the corundum worm through the gear box and vertical shaft of the machine, a pulley is fixed directly on the spindle of the corundum worm itself. By this means the effects of the torsion of the shafts are got rid of. The corundum worm is revolved at a speed of 2,400 revolutions per minute, and it is geared up to the work table through change wheels as in a hobbing machine. A rapid down ward feed is provided for, and the driving belt is led horizontally to the driving pulley to permit this.

The author has ground up several cast-iron wheels of 7 pitch on the experimental machine. The wheels are first hobbed, but the hob is not put into the full depth, so that a few thousandths of an inch are left on the sides of the teeth for grinding off. Before the wheels are ground the bottoms of the teeth are cut to the full depth with a special formed cutter. It would of course be far better to hob the teeth in one operation with a hob having teeth that are slightly too thin. The wheel is then put on the worl mandrel, and the corundum worm moved down by hand until its centre is level with the top of the wheel to be ground. The corundum worm is then adjusted endwise by means of a screw turned by a worm and worm wheel by which a very fine cut can be put on, so that one side of the thread touches one side of the teeth in the wheel. Owing to 
the thread on the corundum worm being thin, as has been explained, the other side of the thread is not in contact with the teeth. The corundum worm is then allowed to feed down automatically, grinding up one side of all the teeth and generating them truly. The machine is then stopped, the corundum worm raised by hand, and a finishing cut taken. The other sides of the teeth are ground and finished in the same way. A stream of lubricant consisting of water, soda and oil is kept running on the wheel to prevent glazing.

In the best results obtained so far a cast-iron wheel of 70 teeth 7 pitch and $1 \frac{1}{4}$ inches face was completely ground in eight minutes.

The wear on the corundum worm appears to be very slight, about $\frac{1}{1000}$ inch in the worst part, but in the finished machine it is proposed to provide a carborundum wheel for touching up the corundum worm after each cut. The author has found that when he grinds $r \frac{i}{100}$ inch off the corundum worm to true it up, the carborundum wheel which grinds it shows only $\frac{1}{4000}$ inch of wear. The author has also found that the corundum worm is only worn on three threads for about one-third of their circumference. In the finished machine an arrangement will be provided for traversing the wheel that is being ground across the face of the corundum worm, like a wheel meshing with a rack, thereby wearing the corundum worm evenly. 'To compensate for this traversing motion, a differential gear will have to be provided like that of the Reinecker machine when cutting worm wheels with a taper hob. The results obtained with the experimental machine have been so good that with these improvements there is every prospect of the success of a future machine.

Conclusion.-The author's idea is that not case-hardened wheels only should be ground on this machine, but every kind of metal should be ground in the soft state, no matter for what purpose the wheels are required. The wheels would be roughed out rapidly in the gear hobbing machine with no attempt at finish, and then sent to the grinding machine to be finished, just as all lathe work that is required to be both accurate and cheaply produced, is first roughed out in the lathe and then finished on the universal grinder. 
The author's best thanks are due to those firms and others who, by their courtesy in supplying him with information, photographs and exhibits, have materially assisted him in the preparation of this Paper.

The Paper is illustrated by Plates 21 to 27 and 5 Figs. in the letterpress.

\section{Discussion.}

On the motion of the President, a hearty vote of thanks was accorded to Mr. Humpage for his interesting Paper.

Mr. Christophar W. James, in opening the discussion, thought the author had pointed out the chief trouble of the system of generating gears by means of hobs. The final method of grinding seemed to him to be eminently practicable for case-hardened gearing, but he failed to see that for ordinary gearing of cast-iron or soft materials he was likely to attain any greater accuracy by his grinding arrangement than by means of steel cutters, because the amount of wear upon the corundum wheel would be perceptibly more than the wear on the steel tools. For himself he was inclined to think that the difficulty of the inequality of expansion or contraction that might take place in hardening a hob, which was extremely difficult to get over, might be evaded by the adoption of a totally different system, namely, that of planing or shaping the teeth. If that were done with a simple tool, that is, a tool more or less of the character of a lathe or slotting tool, which could be hardened and subsequently ground to any desired degree of accuracy, the inclination of the sides could be made anything that was suitable for the gear in question. He by no means took the riew that any one angle was necessarily correct for the angle of obliquity, and he thought such an angle required to be regulated according to the purpose for which the gear was intended. It was perfectly practicable to make a machine operating with a single tool of the sort described which 
(Mr. Christopher W. James.)

would truly generate the shapes of the teeth. At the present time his firm was engaged in the manufacture of a machine of that character, but it was not at present in a state which would enable him to describe it in detail to the members. Its principle, however, was well known. He thought that method of shaping teeth was very nearly as quick in operation as the hobbing machine, because with the slotting action of a tool of that sort much heavier cuts could be taken than could be taken with the milling action of the ordinary hob.

Mr. Alfred Saxon thought the author had certainly shown some resource in the early stages of the Paper, when dealing with the historical aspect of the question, in trying to explain his idea of how spur-gearing was originally introduced. He did not know whether the author had consulted Fairbairn, who wrote a very good book dealing with the early history of gearing. There could be no doubt, however, that the first gearing made on any large scale was carried out by the Manchester engineers in connection with corn and cotton mills, and other industries. In textile mills the practice of applying spur-gearing for main driving was gradually dying out, and was being substituted by other forms of driving, such as rope driving, strap driving, and electrical driving.

He thought the author had not explained the whole of the reasons connected with the adoption of the mortice wheel. The author said (page 653) "For heavy work the millwright introduced an iron wheel with spurs on the rim, cast in one piece," and did not make any reference at all to the large driving wheels which were made from a full segment pattern and built up, and that those wheels were only comparatively small driving wheels, which were made whole. He, therefore, suggested to the author that he might add to that portion of the Paper that wheels were also made of segments made from a full segment pattern, the mortice wheels being used as pinions. The author left the question rather open to doubt as to what the purpose of the mortice wheel was. It was undoubtedly adopted to give smooth and noiseless running, but in starting and stopping there was a considerable amount of backlash, and with iron 
pinions it was very frequently found there was a tooth out when an inspection was made of the gearing after stopping time. That was found to be the case particularly where engines were coupled. When high-pressure engines were applied to existing condensing engines and coupled on to second-motion shafts, it was found to be almost a necessity for mortice pinions to be introduced to avoid the breaking of teeth through the shocks caused. Those were amongst the reasons for using mortice wheels, and, as the author said, there were wheels of that kind running today, and running very satisfactorily.

Reference was made on page 656 to some special forms of cutters which were shown in Fig. 12, Plate 22, and mention was made of milling cutters made in segments. In his firm's works they formerly had a wheel-cutting machine of the exact type of that shown in Fig. 10, Plate 22, and more than thirty years ago he occasionally worked on that very machine. He believed it was bought at a sale by his father, and there were boxes of the various types of cutters which the author referred to, particularly the segment cutters. The machine was used for cutting replace change and other small wheels for the various lathes and machines in the works. It was afterwards broken up, and some portions of it were used for milling key-ways in the coupling ends of shafting for a time.

The author referred on page 662 to the double helical spurgearing which MLessrs. P. R. Jackson and Co. introduced. That style of gearing undoubtedly had great advantages for strength and ease of working, but it also possessed disadvantages. It was frequently found in cotton mill practice, where long second-motion shafts were in use to which were secured other wheels for driving the card-room line shafts and upright shaft, that the helical type of gear created a certain amount of end-play, thus causing the bevel wheels fixed on the shafts to work with a varying depth of gear. A certain amount of end-play had to be allowed for in helical gearing of large size, and this was accomplished by applying expansion couplings at the end of the portion of the second-motion shaft on which the pinionwheel was tixer. 
(Mr. Alfred Saxon).

The author had not referred to another style of tooth that was introduced by a member of the firm of Messrs. P. R. Jackson and Co., which was known originally as the "Gee" tooth; it was also known as the buttress or the sloping-back tooth. This form of tooth gave increased strength compared with the ordinary form of tonth.

Mr. Emart C. Amos proposed to confine himself to one point, and that a very elementary one. He believed he was right in saying there were three methods of cutting teeth: (1) By shaping or planing, (2) by a disc-cutter, and (3) by a hobbing machine. The author had mentioned the disadvantages of the disc milling-cutter and of the hobbing machine, nor did he appear to be in favour of the planing machine principle. He also stated that he had adopted a machine which he thought was the best, and that it was of the hobbingmachine type. He (the speaker) thought it would be most interesting if it were possible to ascertain the general consensus of opinion of the meeting as to whether planing, milling, or hobbing was the best known method today of cutting spur-gears. He himself felt that the author's method of hobbing, in combination with an emery grinder, was a good method.

Mr. L. A. LEgros said that in motor-car practice a very great deal of difficulty was met with in cutting the teeth so as to be exactly correct in shape after they had been case-hardened. The wheels used in motor-cars were made of special steels, and had to be case-hardened to a considerable depth in order to stand the excessive pressure to which they were subjected; and in casehardening, in spite of the precautions which were taken, they went somewhat out of shape.

He thought the anthor of the Paper had touched on a most, important subject when he suggested that wheels should be finished by grinding, and that his remarks applied not to heavy mill gear, which could be finished in the old way, but to those wheels which were used in high-speed machinery. The wheel went out of shape in case-hardening; sometimes it went a little eccentric, but generally it went elliptical and buckled somewhat. Bevel gears were particularly 
troublesome. In the method adopted by the speaker's firm, the teeth were machined and the wheel treated in the case-hardening furnace and annealed, leaving a very large amount to be turned off after the wheel had been treated in the case-hardening furnace. The rest of the wheel was then machined to a considerable extent; then the teeth were hardened and the wheel machined again true to the finished teeth; that is, the bore and faces were trued to the teeth. In spite of that, distortion was still left in the wheel, and it was that distortion which could be removed by grinding only one-thousandth or two-thousandths of an inch away from the tooth. By removing that small amount he thought the wheels would be made quite quiet, where at present there was some slight noise. With spur-gearing a machine had been brought out by one of the German firms, Messrs. Reinecker, for grinding those teeth, and it was probable that for bevel gearing a similar machine would be of use.

Mr. Lours W. Sмiтн said that not very long ago he had much difficulty in deciding the best way of cutting cast-steel gears, because cast steel was not always equal in quality, but had hard places in it. He was in doubt as to whether it would not be best to nse the hob, which was acknowledged to be the most accurate way for bronze and cast-iron. The question arose, however, owing to the difficulty of the inequality in steel, as to whether it was not too expensive to go in for hobs, even although gears of only a certain number of teeth had to be dealt with, which did not necessarily mean that it was compulsory to provide the whole eight cutters of a certain pitch, but only one or two. Under those circumstances it was questionable whether it was not cheaper to put an ordinary automatic gear-cutter down than the one the author recommended. He found, on making numerous tests about a year ago on some steel castings, that the whole cost in a year, of taking the hobs, the cutters and the speeds on the one machine as against the other, came out in favour of the single-dise cutter, although he quite acknowledged that for bronze and cast-iron and such materials bobbing was by far the best and most accurate method. 
(Mr. Louis W, Smith.)

Those engineers who were not quite familiar with regard to motor-car work must have been very much interested in the grinding operation which the author had so clearly explained, but he supposed that that would only be applicable up to very small pitches. $\mathrm{He}$ thought the leading point in the Paper for the future was the special hob with the teeth let in, which had been fully explained. In his opinion there was absolutely no doubt that the hobbing of spurwheels was quite established, and that the cutter of the future was one with high-speed inserted teeth, which got over the difficulty of cracked cutters and heavy expense in material.

Mr. E. A. Rainer thought that, as a good deal had been said about grinding, it might interest the members to know some of the experience his firm had had with regard to motor-car work. $\mathrm{He}$ thought, as most people did, that if they could only get a casehardened gear true it would run quietly. He was sorry to say their experience did not bear out that assumption, and they had come to the conclusion that grinding, from a sound point of view, was of no advantage. They had found grinding to be satisfactory in the way the author had mentioned. It was possible to rough out a blank and grind it to shape after case-hardening. That certainly was an economical process; very good wheels could be turned out much cheaper, but he did not think they were any quieter. Perhaps with No. 4 or No. 5 Brown and Sharpe pitches, grinding was an advantage ; the experience of his firm was that in smaller pitches, such as No. 6 or No. 7 Brown and Sharpe, grinding would not make the wheels any quieter, and he knew in several cases that other firms had thrown out gear grinders.

Mr. P. J. Worscer, Jun., said that in the course of his experience he had had a good deal to do with high-speed machinery, in which very small gears were used, running at a great rate, and it had been found necessary to make them as accurately as possible. He had had the advantage of seeing the hob which the author had described, and he would like to add his testimony to the extreme ingenuity which had been brought to bear in its construction. At 
the same time, he thought it was quite likely to carry a great deal of trouble with it. All engineers knew what a hob was if it was made out of the solid. It was not a very easy thing to make, as it had to be machine relieved or backed-off all over, both on the top and the sides of the teeth. In the author's hob those teeth were inserted blades, and, as had been deseribed, the blades could be taken out, ground all over and put back again. That seemed an advantage, but it meant that each of the blades was practically a piece of a spiral, that is, it looked very much like one of the blades on a mowing machine. If that were taken out and ground all over so that it fitted into a spiral groove, it would be found it was an exceedingly difficult operation to perform. He thought the difficulty in correctly grinding that spiral tooth, more especially the part of the spiral tooth which fitted into the core of the hob, was more difficult than getting the solid hob tooth to the correct form. The author assumed that the difficulty of hardening a hob and obtaining the correct form after it had been hardened could not be overcome, but with the more recent methods of hardening, in which pyrometers could be used and in which certain temperatures could be much more accurately maintained, many of the difficulties of distorted hobs could be overcome. He thought there was still a great probability that the solid hob would be more useful for the hobbing machine than the hob with inserted teeth.

Mr. Danier Adamson desired to bring to the notico of the author one din̂ficulty in connection with spur-gearing, in the hope that some guidance would be given to the members on the subject. $\mathrm{He}$ referred to the fixing of a standard of inaccuracy for spur-gearing, or what was understood as a limit of error and some means by which it could be measured. Great attention had been given to the subject of limits of error for diameters and lengths by the Engineering Standards Committee, but he had not yet met with any generally accepted means for deciding whether a spur-wheel was accurately cut or not. For instance, it was very essential that the pitch of change-wheels should be accurate, not only from one tooth to another, but between any two teeth on the wheel up to half the circumference. 
(Mr. Daniel Adamson.)

He suggested, for the author to criticise as a basis for a reasonable limit, one ten-thousandth of an inch per inch in diameter under or over the correct pitch; that is, if the wheel were 10 inches in diameter he suggested that no two teeth, either two adjacent teeth or any two teeth up to half the circumference of the wheel, should be away from the correct pitch by more than one thousandth of an inch under or over, the limit of error being $\frac{1}{50 \mathrm{v}}$ inch. That limit he found was commercially obtainable. It might be the case that it was too large a limit, but it was evidently not too fine, because it had been obtained upon cut wheels without grinding.

Mr. WaLten Deakin thought the subject the author had introduced was of great interest to all the members, because the demand for correct gearing was increasing every day. Many of the points that had been mentioned in the Paper had been brought to light as the result of the demand for silent gearing in motor-cars. People were satisfied with very indifferent gearing years ago, and until the motor business had been considerably developed, ordinary cut-gearing satisfied the requirements of most people; but the quality of the gearing requisite in motor-cars had directed attention to the question of accuracy to a greater extent than had hitherto been the case.

There was one point in the Paper he would like to criticise with reference to the relative advantages of gearing cut by ordinary automatic gear-cutters and the hobbing process, which the author had particularly brought under their notice. It was stated (page 673), in enumerating the disadrantages of disc milling-cutters, that "as the cutter gets blunt, the centres of the cutter and work mandrel are forced apart, and the bottoms of the teeth describe a slight scroll." That was quite true with reference to the particular form of machine to which the author referred, but it was equally true with reference to the hobbing machine. It had been the experience of some motorcar builders that, after having milled out the teeth on the hobbing machine, it was necessary for them to put the wheels into an ordinary automatic gear-cutting machine and correct them. A great deal of that trouble arose from the expansion due to the bluntness of the 
cutters. In both cases he would suppose for the moment a commencement was made with a cold wheel and a cold hob, and after cutting was begun a large amount of heat was generated. That heat expanded the cutter into the wheel, and expanded the wheel blank on to the cutter. Both these processes took place in either of the machines. The author had said in reference to the hobbing machine, that with a good stiff machine, from two to three times the amount of metal could be removed per hour as with a machine using a disc milling-cutter of the same pitch. The metal could be removed, but when it was removed at such a rapid pace the element of inaccuracy was introduced, which all engineers desired to eliminate. If inaccuracy was to be eliminated, it was necessary that the work should be done slower. He thought the author appreciated that point, inasmuch as he had introduced a grinding-machine for correcting the inaccuracy resulting from that expansion. In dealing with that question he thought it would be a good thing to devise something effectually to take away the heat, and in that way one element of inaccuracy would be removed. That might be accomplished by a blast of cold air where lubrication was impracticable; but that did not do away with the difficulty of the bluntness of the teeth caused by the cutting action. In a hobbingmachine, although the hob gradually cut the whole circumference of the wheel as it rotated, when it got to the bottom of the teeth, the cutter, althóugh it was a hob cutter, must necessarily be subject to the same disadvantages as the single cutter ; that is, it became blunt by reason of the work it had done. So that, with regard to the superiority of one machine over the other, he did not think there was any difference between them; they would each produce inaccurate work if unduly forced.

With reference to the question of building up the hob for the generating machine, he thought that was open to a great many objections from a practical point of view. First of all there was the difficulty of getting the parts absolutely right, and from a practical point of view he did not feel at all sanguine as to the future of the made-up hob. The better plan would be to eliminate as far as possible the inaccuracies in the hardening. It was much better to 
(Mr, Walter Deakin.)

throw one or two hobs away and get a right one, rather than to fix their hope upon a hob which was built up in pieces like the one which had been exhibited.

The description of the grinding-machine was very interesting, but personally he would like to see some practical results. In doing the work, it was necessary to get an abrasive material like corundum or something of that eharacter, and form it more accurately than the cutter was formed, and constantly maintain it, if more accurate results were to be obtained; and he had not seen an abrasive wheel yet that did not wear. It was an interesting problem, and if the author had solved it he was sure every member would be grateful to him for his efforts. Personally he felt rather pessimistic about the solution of the problem in the way the author had suggested. Many attempts were made before wheels were cut by machines to correct them by grinding, and most of those attempts were failures. It must be said in favour of the proposal, however, that at the time he referred to, many of the abrasive materials were not of the excellent quality which were obtainable at the present time.

Mr. J. J. Podesta, having ascertained that the author used a positive gear mechanism between the cutter and the blank, gave an item of personal experience showing the necessity for this. A worm-wheel was to be cut in the lathe. The blank was turned so as to give 100 $V$ teeth at ${ }_{1}^{5}$ inch pitch on the pitch-line. The hob was made with a $V$ thread of the same pitch and run between the lathe certres. The wheel-blank was mounted on the slide-rest, and rotated simply by the obliquity of the hob teeth. The hob of course began cutting at the point where the top of the teeth would be when the wheel was finished, and so the $\frac{5}{16}$ inch was marked off, not on the pitchline, but at the tops of the teeth. Then too there must have occurred some slip, as the final result was 108 teeth. The special job in land did not necessitate the rejection of the wheel, otherwise there might have been an interesting inquiry to ascertain exactly where those extra 8 teeth came from.

Mr. Thomas Clarkson thought it seemed rather extraordinary that, at the present time, engineers should be discussing gearing and 
the best way to cut teeth. But it was obvious that gearing was a subject which interested all classes of mechanical engineers, because it applied in such a variety of ways, from light, delicate watch mechanism to machine tools and heavy gearing used in mills. The hobbing appeared to be a natural development in the construction of a worm-wheel applied to a spur-wheel. He remombered many years ago, when he worked the Whitworth wheel-cutter, he got wormwheels with a straight tooth cut with a single milling-cutter. Then at a further stage engineers began to cut their worm-wheels with a hob which gave larger bearing surfaces, while the next development was the application of putting the hob on the skew and getting a spur-wheel. He believed a great deal of the difficulty in getting an accurate spur-wheel with a hob lay in the hob itself. First of all, it was a difficult thing to make, as the members had already heard, and part of that difficulty lay in the hardening operation, especially if the hobs were large. Of course, with electrical furnaces and better means of hardening and tempering, the distortion problem would be reduced, but it would be recognised at once by practical men that the mere fact of having a hob rolling theoretically against a disc did not necessarily produce a true form of tooth.

Hardening the gears might be necessary and desirable in some cases, but he preferred to work with non-hardened gears, as he thought the result was not only quieter but was steadior in every way. Personally he did not use hardened gears. All engineers recognised the difficulties of grinding in ordinary cylindrical work, and in some cases it might be justifiable for gears. The principal difficulty makers had was with reference to bevels, which were expensive to make. They became distorted in the hardening operation; they had to be softened again in order to straighten them, and that did away to a large extent with the benefit of the hardening operation. $\mathrm{He}$ himself was using a non-hardened pinion, that is, a high grade nonhardened steel against a phosphor-bronze wheel.

Some years ago, when he thought of using a turbine for driving a steam-car, the question of reduction of speed at once came to the fore. He looked into the matter to some extent, and found that De Laval, who was using a turbine for driving machinery, used two 
(Mr. Thomas Clarkson.)

screws forming really an extended double helical tooth, and he had seen the pinions running at several thousand revolutions a minute with practically no noise at all. The metal was not hardened, but it was very well lubricated. He thought, if the non-hardened gears were encased, the dust kept out, and clean oil kept in, they would last a very long time and give no trouble. Distortion or cracking was always liable to oceur with hardened gears.

Mr. William H. Alien, Member of Couneil, thought the Paper had raised a deeply interesting diseussion, which had led up to the great existing difficulty engineers experienced in running small wheels to the pitch of perfection which was now required. The author suggested that Fig. 2, Plate 21, depicted the earliest form of gearing. He did not know whether Mr. Humpage had travelled in the East; if he had he would have found in India, Persia, Mesopotamia and Egypt that that kind of wheel was in rogue at the present time, not as a relic of the old days but as a present-day process of manufacture. In going from Alexandria to Khartoum one noticed many thousands of those wheels at work on the Nile in the form of Sakiehs. He was surprised at seeing in the streets of Cairo quite a large industry being carried on with that particular form of gearing. His attention was called to the subject by seeing a log being attacked with a saw and an axe by a man in the street. He asked the Arab carpenter what he was going to do with it, and was told that in the course of three days it would be made into a trueshaped wheol. On visiting the man three days afterwards he was astonished at the remarkably quick way in which the man had converted the tree into a wheel as shown in Fig. 2. The following day he visited Heliopolis and saw the wheel at work. He doubted whether Manchester could do better than that at the present day. The words appeared above the author's drawing "Suggested earliest form of gearing." No doubt that was the earliest form of gearing, but it was an industry to-day.

Mr. William Sisson said it seemed to him from his standpoint that the grinding of small gears was a sort of counsel of despair. 
The problem had been set by motor-car engineers, and very great credit was due to the author for the way in which he had dealt with it. He did not think, however, that engineers should be asked to tackle such a problem. Motor-car people treated their gears in a rough way which ordinary engineers with a conscience would never think of-he meant a mechanical conscience. He thought it would have been far better, if all the effervescence of ingenuity on the motor-car business had been directed to getting an engine that would work without a change-gear box something like the locomotive; engineers could not improve upon that.

With regard to the history of the subject, he remembered years ago being at the Hayle Foundry where large engines for pumping out Haarlem Lake were built, and there saw something which interested him greatly, namely a mortice worm-wheel on a boring machine. It had a cast-iron worm, but the worm-wheel was cogged with wood. Arising out of that, he could not help thinking that Mr. Saxon was not quite right in saying that the iron tooth wheel was always the largest. As far as he knew, the cogged or mortice wheel of a pair was usually the larger, on the ground of both strength and durability; the former because the root thickness of the tooth of the larger wheel was greater than that of the pinion or smaller wheel. and the latter because the greater number of teeth in the wheel distributed the wear of tho wood teeth.

With regard to hobbing, he wished to ask what angle the worm on the hob shaft was set to. There were an infinite number of spirals on the tooth: to which spiral angle did he set the axis of the hob, and what size was the worm hob made in proportion to the pitch? It ought to be an infinite diameter in theory, but if it were made very small it was quite certain that it would be impossible to cut deeper properly because it would foul. There must be a sort of compromise in the size of the worm-eutter, the generating cylinder so to speak, in proportion to the pitch.

Mr. Chafles Pendlebury, in dealing with the historical part of the Paper, said he noticed that Messrs. Gould and Eberhardt were credited (page 662) with bringing out presumably the first automatic 
(.Vr. Charles Pendlebury.)

gear-cutting machine. He happened to know personally that Messrs. Craven Brothers, of Manchester, so long ago as 1877 made an absolutely automatic gear-cutting machine which was used in connection with change wheels for cotton spinning. It was on very much the same lines as the present one, but he did not know the name of the inventor.

Mr. Hompage, in reply, said that Mr. Christopher James had pointed ont that his firm was making a machine which he presumed was not a hobbing machine, but a machine with a single cutter or cutters. If Mr. James would cut a big wheel having a large number of teeth, with a single formed cutter, he would find that by the time he got round the wheel the cutting edges would have worn considerably. He was inclined to think that the more cutting points on a cutter, if they all did their duty, meant a longer life for the cutter and more accuracy in the wheel when it was finished. In reply to Mr. Saxon's remarks, it was of course impossible for him to deal in his Paper with everything that he knew on the subject. $\mathrm{Mr}$. Saxon had lived and worked in his particular line of business, and knew considerably more about it than the author. He only spoke from his own knowledge, and the information that he could get from others. Large gearing had undoabtedly been replaced by cotton ropes and belts, owing to the great demand for higher speeds with less noise. When however large wheels could be more accurately machined and the cost and noise rednced, they would gradually come into favour again, owing to their efficiency being at least 10 per cent. higher, and their cost of maintenance considerably less than that of cotton ropes.

In reply to Mr. Amos (page 680), in his opinion better gears could be cut with a hobbing cutter than with any other cutter, because of the number of teeth in the hob. He did not think the single or dise cutter had a chance with the hobbing cutter for either quantity or quality of work done, a point he would deal with later on when referring to hard metals.

In reply to Mr. Legros, up to the present time the wheels he had ground had been small, as he had only been at work on his idea 
for a few months. He did not mean to say that his machine would revolutionise the world so far as that kind of work was concerned. He did not know at present what its limits were, because it was in its very early stages, but up to the present time after hobbing wheels, and also cutting them with single cutters, he could always show an improvement by his method of grinding, both in soft wheels and in hard wheels. Since writing the Paper he had dealt with some case-hardened wheels for one of the leading motor-car manufacturers which were as much as $\frac{1}{32}$ inch oval after hardening, and in his opinion had made a very good job of them. Running them as high as he could with a fairly good load he could not hear the teeth at all; they were absolutely as silent as a belt. He did not say, however, that they were absolutely perfect; but a good deal more time was spent on the wheels than the ones referred to in his Paper, namely, eight minutes. This however was a natural result, as they were the first case-hardened wheels he had ever dealt with. He believed the wear on the corundum worm was very little indeed. He ground a pair of wheels, and after examination he could not detect more than $\frac{1}{1000^{t}}$ th of an inch of wear, although he shifted the cornndum worm after each wheel had been ground. But as the members would understand, it made a mark on the corundum worm starting from the right-hand side down the thread, from the top to the bottom and up again, so that about one-third or one-fourth of the circumference of the corundum worm showed a line just as if a black lead pencil had been drawn down it. That could be improved if the wheel was traversed across the face of the corrundum worm at the same rate, like $a$ wheel meshing with a rack.

With regard to Mr. L. W. Smith's remarks (page 681), there could be no doubt that hard wheels were more diffeult to cut, and punished the cutters more than those in softer metals. If the cutting edge of a tooth in the hob were dull or broken, a piece of metal was left on each involute tooth; but if the man who was working the hobbing machine would turn the cutter round one-tenth or one-twelfth of its revolution for every wheel cut, he brought other teeth of the hob into use that were not doing so much work, and in that way the cutter could be made to last abont ten to trenty times as long. He 
(Mr. Humpage.)

believed that was not generally understood by people who worked hobbing machines; they thought there were plenty of teeth and it did not matter, but when the hobs were examinod after half a dozen wheels had been cut it would be found that there were one or two teeth only with their corners worn. He advised those who worked the machine to move the hob round. It did not take a minute to perform that operation, and the life of the cutter was thereby greatly lengthened; while better working was obtained. As it was an expensive tool, very special care was required, otherwise the up-keep of the cutters would run into a big item.

He had very little experience of cutting hard steels, and those were for motor-car manufacturers, who used a motal of very high tensile strain, which punished the cutters greatly. It was mentioned in the Paper that if inserted blades were fixed in the body of a hob, and each blade was dealt with separately, they could bo treated better than a solid hob, especially if they were ground all over after hardening. All engineers knew that in working a machine, even after grinding a tool, if an oil stone were rubbed on the sides as well as the top, the roughness would be taken off and a better finish obtained. So it was with a hob. If it were taken straight out of the fire and sand-blasted, only the front of it was ground off; a burr was left on the rest of it, and naturally a very fine finish could not be obtained. He had found in grinding a hob that if a great pressure were brought to bear upon it when it was being sharpened, it threw a considerable burr into the space, and in cutting gun-metal wheels he found that these burrs did not wear off until the hob got half an inch down the face of the wheel. That required to be looked after, as in the ordinary cutter, by the man who had charge of the machine.

With regard to Mr. Rainer's remarks (page 682), the method adopted by Mr. Rainer's firm was evidently that of grinding one tooth at a time, and, if this were so, the author quite agreed that it would be impossible to make silent running gears, but he still maintained that his own system of generating all teeth simultaneously, as described in the Paper, after being roughed out by the hobbing machine, was the best method of getting silent running gears. In his own case he put the feed on about six times the rate of 
the ordinary gear cutter for roughing, which was a considerable saving in time, as one did not trouble so much about the finish, because that was left to the grinder. All ongineers knew that after a wheel had been cut with teeth it was often found out of truth. Therefore to try and finish that wheel at one cut, in any machine, even in a hobbing machine, which was the best known method, was wrong. Two cuts or more as they knew were taken off every spindle to make a good job, and it should be so with the teeth of gear wheels.

In reply to Mr. Worsley, when he saw the hob in its original state, the blades were inserted in spiral grooves naturally following the same system as the solid hob, so that, when the hob was tilted up, the slot between the teeth was horizontal. In the second type of cutter as exhibited the blades were not made in that fashion at all; the grooves and the blades were absolutely straight, and there was no spiral at all, which cheapened the manufacture. In this particular case the hob was not inclined at all, but it was simply put horizontally in the hobbing machine and allowed to go through; so that the blades were perfect racks in every shape and form. The pitch of the hob in the whole of its length was certainly not a quarter of a thousandth out.

With regard to the question of solid hobs, he lad found them made by very good makers, who used the pyrometer, ctc., to be four to six thousandths out in pitch, and he had even found them out a good deal more than that. He was sure the members would agree with him that it was impossible to cut a correct wheel with an incorrect pitch cutter; any rack that was out of pitch could not possibly work smoothly with a wheel that was of correct pitch. Therefore it seemed to him that to cut a good wheel it was necessary that the tool must be carefully made as regards pitch and angle. Although the point had not been raised, he would like to say that some people had been hollowing out the sides of the cutter, making a curve so that they could take a little more off the points of the teeth. But directly they got off a straight line trouble was experienced, especially in curve making. He was afraid it was more guess work than anything else; a good job might or might not be obtained. He therefore thought the best thing was to keep to a straight, angular side and not to depart from it. 
(11r. Humpage.)

In reply to Mr. Adamson (page 683), he would say that with a good hobbing machine greater accuracy than he had suggested could always be obtained, and by grinding, both the pitch and the involute curves of the teeth were much improved. He would prefer to leave the question of fixing a limit of error to a Committee, if it were considered of sufficient importance.

With regard to Mr. Deakin's remarks (page 684), he did not agree that the hob had the same disadrantage as the disc cutter, because the hob when blunt would cut a slight taper and not a scroll. There was no first and last tooth cut by the hobbing machine, and when cutting steel gears the heat generated was entirely carried away by the lubricant used; therefore the blank and cutter did not expand into each other. When cutting cast-iron gears the heat was evenly generated and distributed and thrown off all round the rim, whereas a disc milling-cutter generated heat in one spot only. Also the hob, having more cutting points, each of which had much less to do, was enabled to distribute the heat, throw it off much more quickly than the disc cutter, and retain its edge much longer. He did not agree that the element of inaccuracy was introduced in removing two or three times the amount of metal, provided that the hob was revolved and fed at a speed which ensured undue heat. This rate of removing metal was always two or three times as fast as the disc milling-cutter of the same pitch.

With respect to the rapid wear of grinding wheels, he would be quite satisfied in getting as good results when grinding the involute teeth of gears, as Mr. Deakin and others had got in finishing spindles and such-like accurate work on their grinding machines. He quite agreed that it was impossible to find any substance that would not wear, but in spite of this wear the most accurate work obtainable was being done by grinding machines. He maintained that a solid hob could not be made so accurate for pitch and with smooth sides and correct angles which finished the involute as the built-up hob described in the Paper.

In regard to Mr. Podesta's questions, as described in the Paper, the blank and hob were suitably geared together.

Mr. Clarkson suggested (page 687) the use of non-hariened gears, 
and he quite agreed with him, but where case-hardened wheels were used he thought grinding the involute teeth after hardening was absolutely necessary.

With regard to Mr. Allen's remarks, he had never seen gears of the crude form shown in Figs. 1 and 2, Plate 21 ; these were entirely his own suggestions, and he was glad to know that something of this kind had actually been made.

In reply to Mr. Sisson, he thought that so long as petrol motors were used for motor-cars, and until something better than changespeed gears to give the speeds required was found, the gear wheels must be made of small size and of light construction to reduce weight, and it was necessary, owing to the heavy duty they had to perform, to case-harden the teeth; therefore grinding with an abrasive wheel could be the only satisfactory way of finishing the teeth. With regard to hobbing, the tangent of the angle to which the axis of the hob shaft was set was found by dividing the circular pitch of the hob by its pitch circumference. The larger the hob, the more cutting points and the greater the accuracy of the work done. the smaller the hob the greater the cutting speed. There was no rule, but the majority of makers adopted the smallest convenient size.

He was interested to learn that Messrs. Craven Brothers, of Manchester, had made an automatic gear cutting machine about the same year as Messrs. Gould and Eberhardt (page 662). 
SPUR-GEARING.

Plate 21.

Fig. 2. Suggested Earliest form of Gearing.

Historical Examples.

I.ig. I.

Suggested Origin.
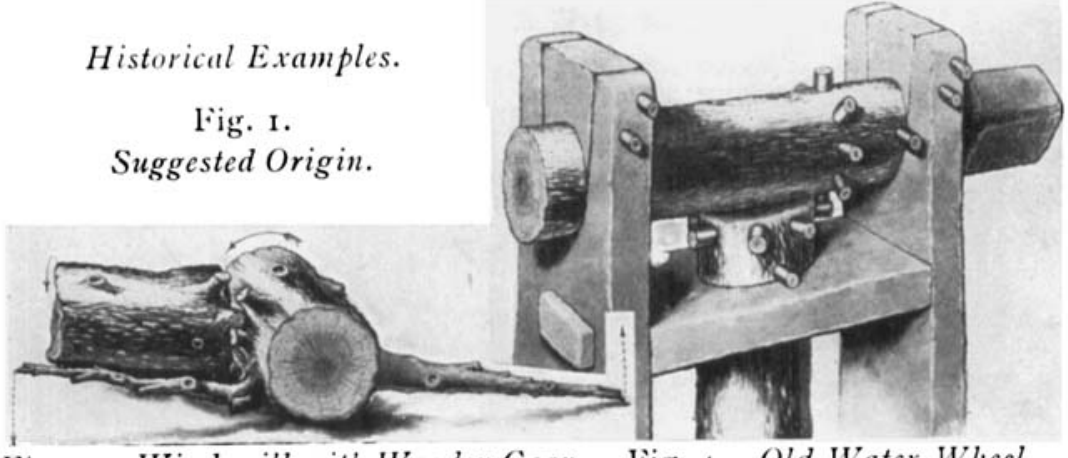

Fig. 3. Wind-mill with Wooden Gear. Fig. 4. Old Water-Wheel.
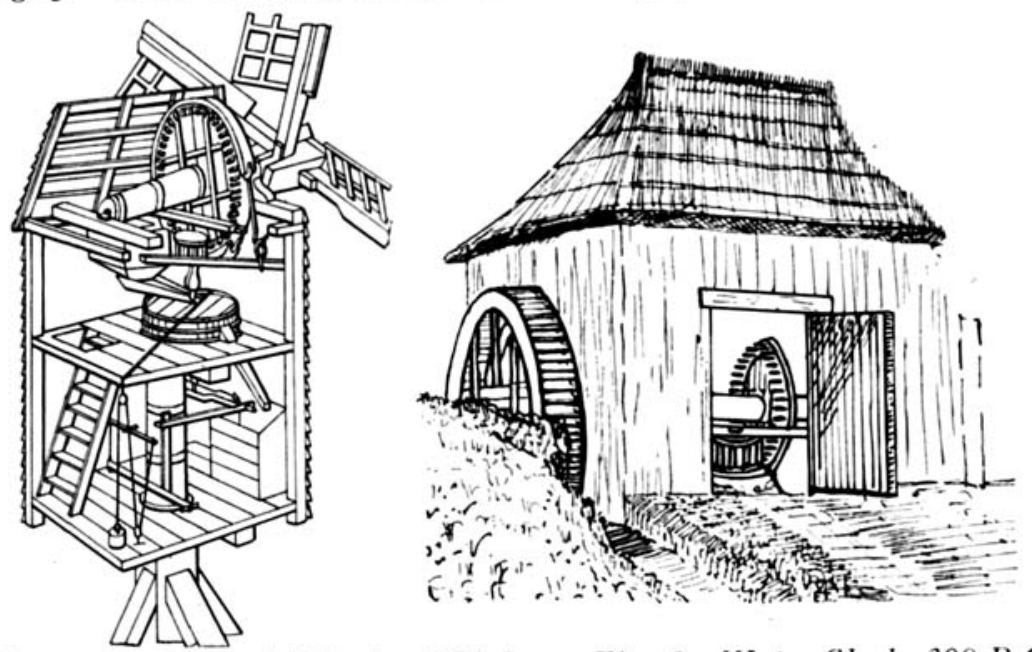

Fig. 5. Hard wood Wheel and Pinion. Fig. 6. Water-Clock, 300 B.C.

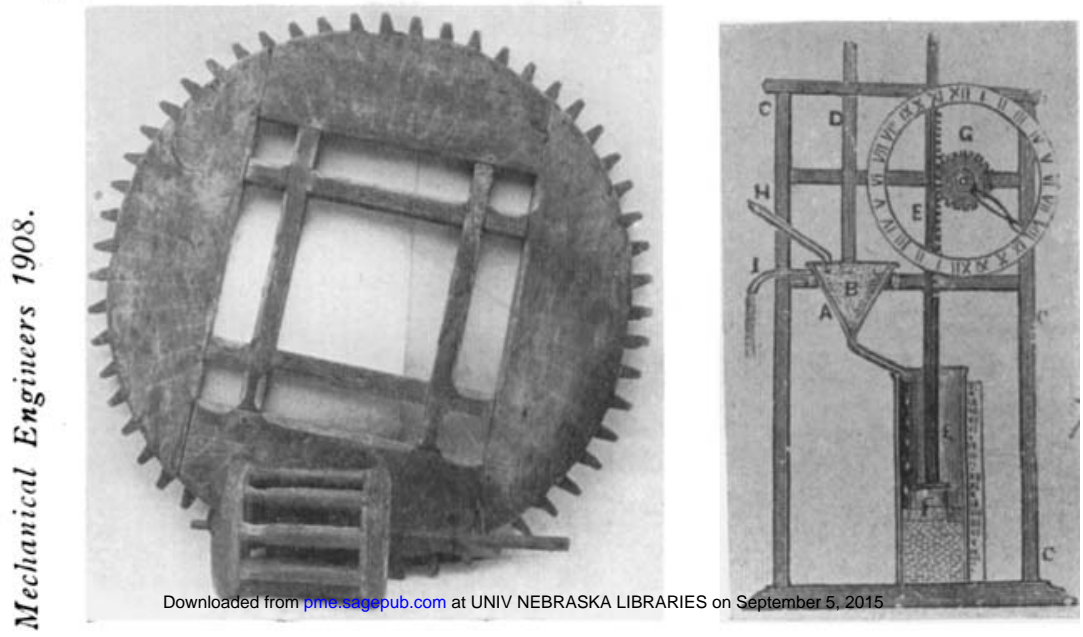


SPUR-GEARING.

Plate 22.

Figs. 7 and 8. 18th Century Whel-Cutting Machines for Clockmakers.

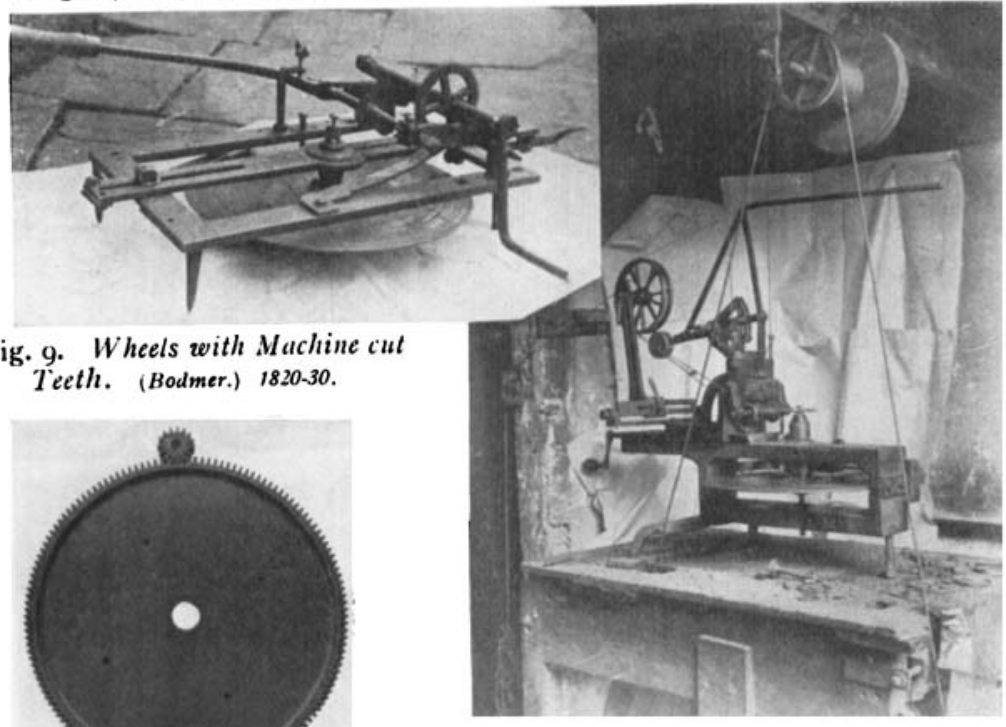

Fig. ro. Wheel-Cutting Machine. A bout 1824.34.

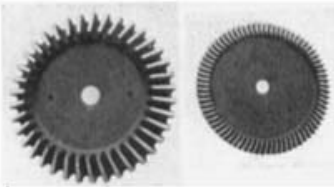

Fig.11. Wheel.Cutting Machine (Whitworth.)/834-44.
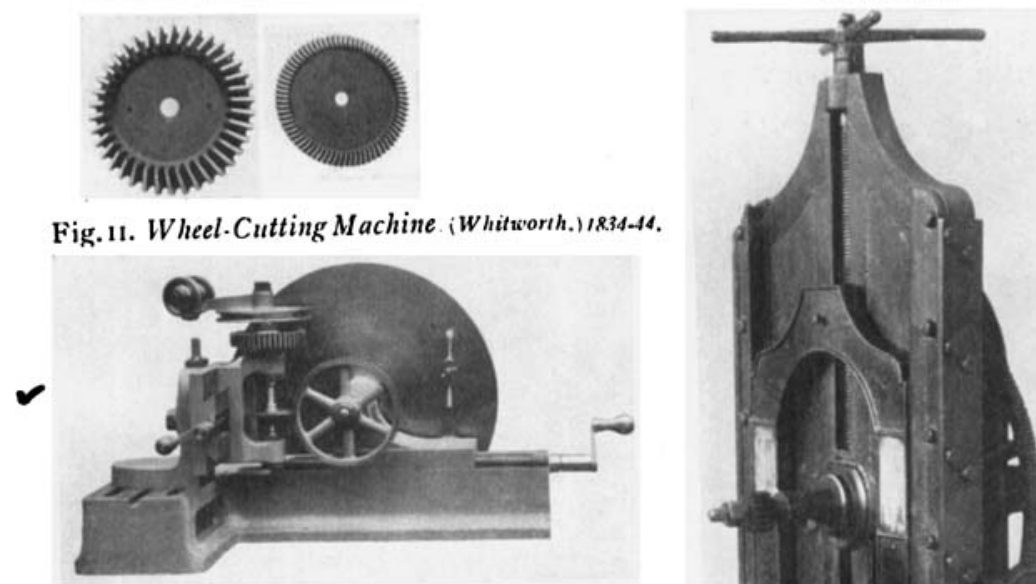

Fig. 12. Cutter. (Bodmer)

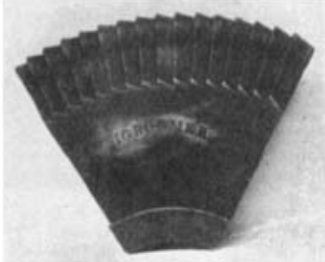

Mechanical

Engineers 1908.

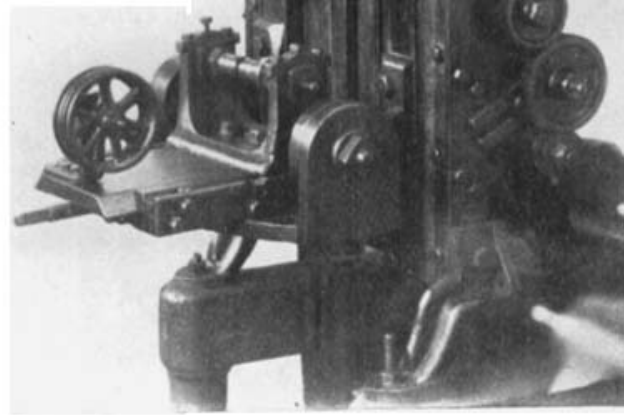

Downloaded from pme.sagepub.com at UNIV NEBRASKA LIBRARIES on September 5, 2015 
SPUR-GEARING.

Plate 23.

Fig. I3. Wheel.Cutting Machine. (Whitworth.)

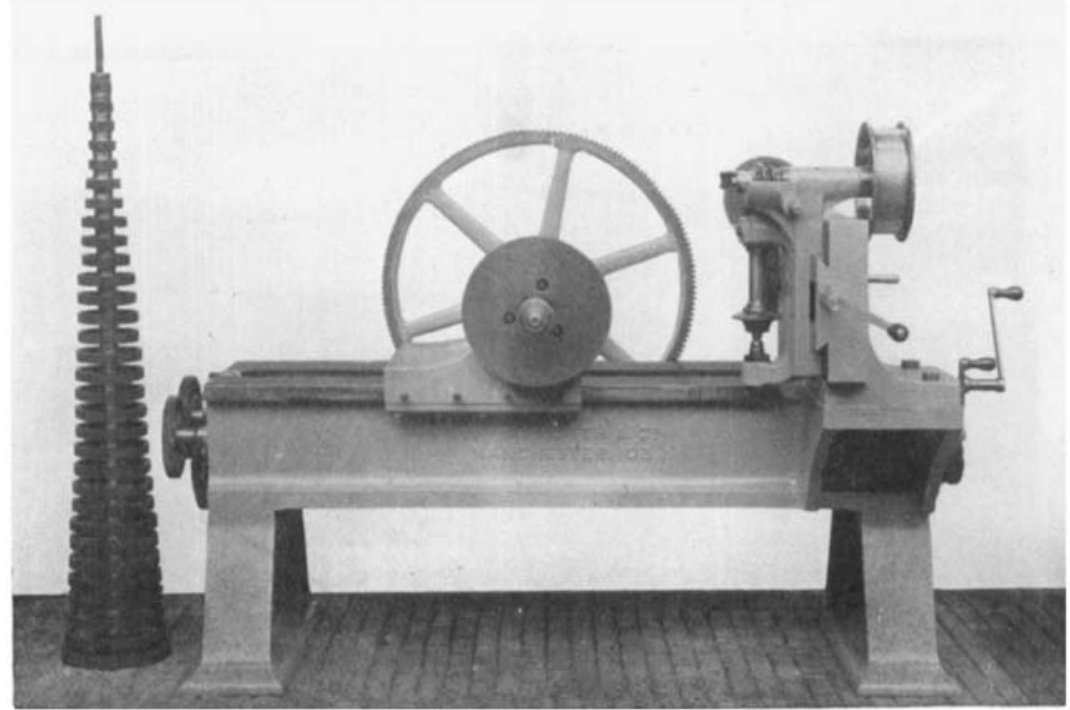

Fig. 15. Machine for Cutting Wheels. (Shepherd, Hill \& Spink.) 1851.

liig. It.

Forming. Machine for

Milling Cutters.
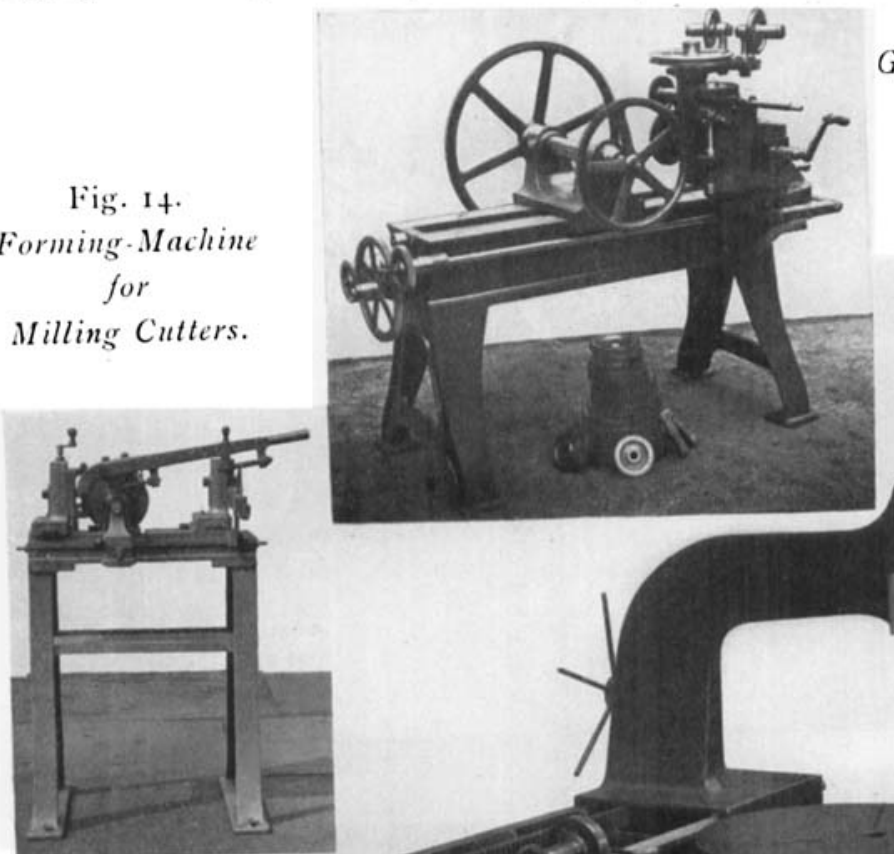

Fig. 16. Gear.Wheel Moulding Machine. (Jackson.) 1854.

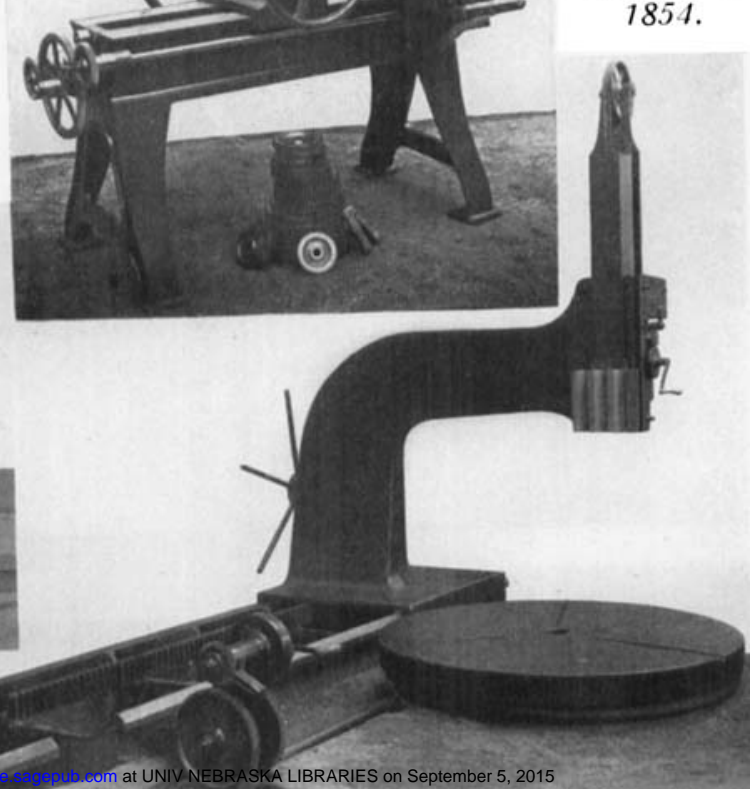

\section{Mechanical} Engineers 1908. 
Fig. 19. Whicel-Cutting Machine. Paris Exhibition, 1867.
Fig. 2o. Cutter and Wheel. Teeth backed off on $a$ Slotter or Shuper.

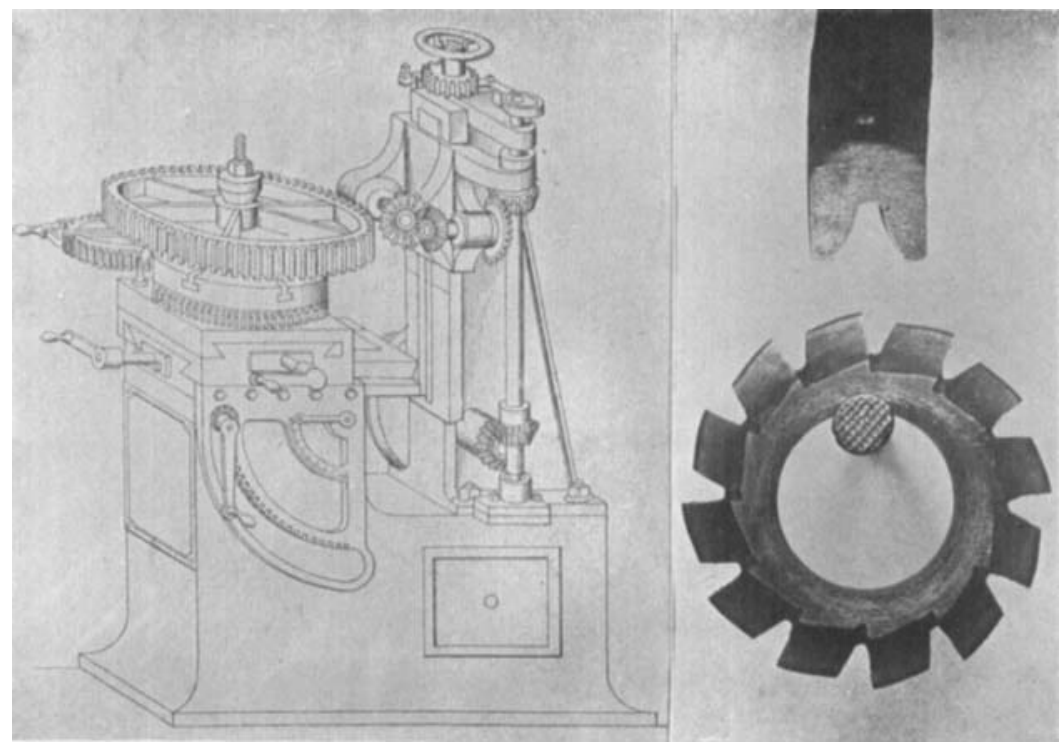

Fig. 21. Spur-Gear Planing Machine. (Gleason.)

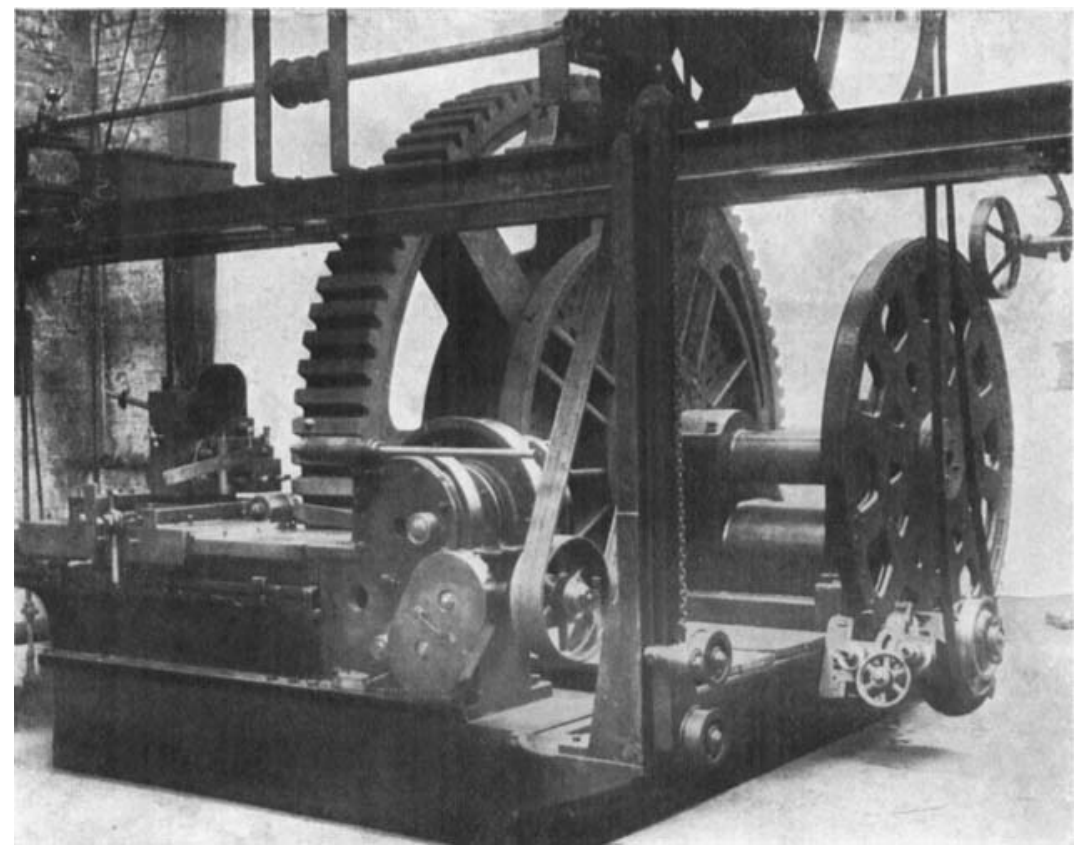

Mechanical Engineers 1908. 
SPUR-GEARING.

Plate 25.

Fig. 22. Gear-Hobbing Machine. (Juenpt.) 1893.

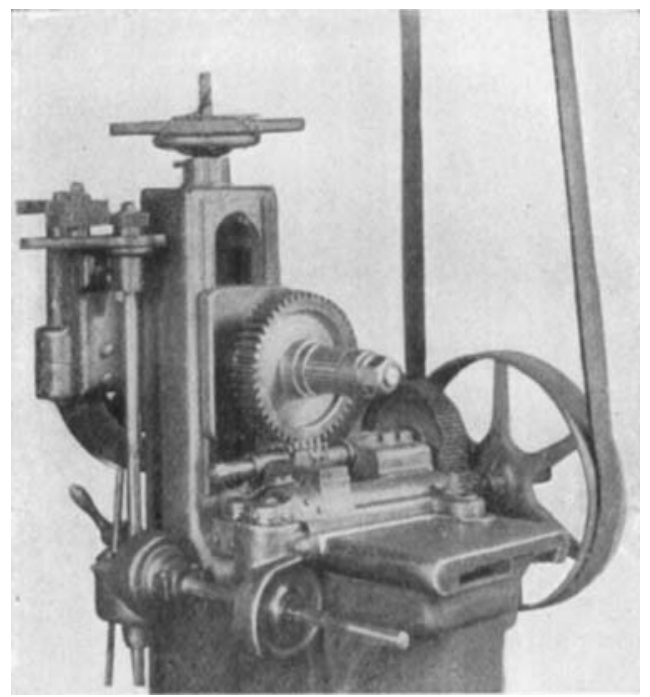

Fig. 23. Gear-Hobbing Machine. (Pficuter.)

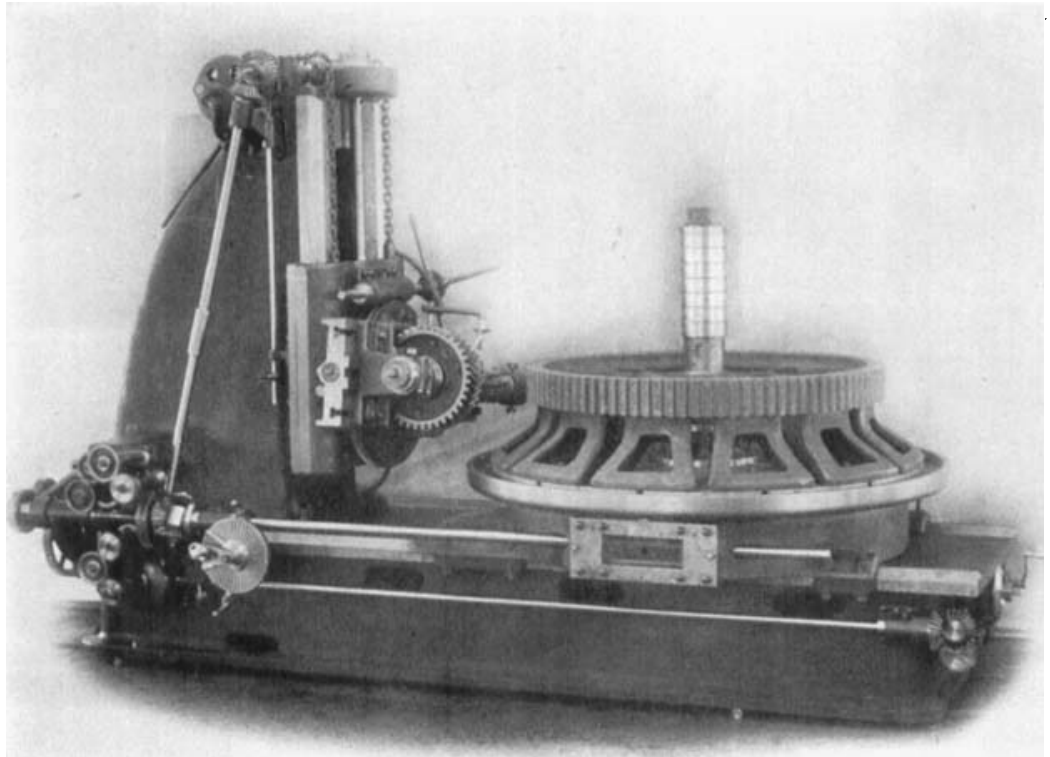


SPUR-GEARING.

Plate 26.

Figr. 24. Gear-Hobbing Machine. (Holroyd.)

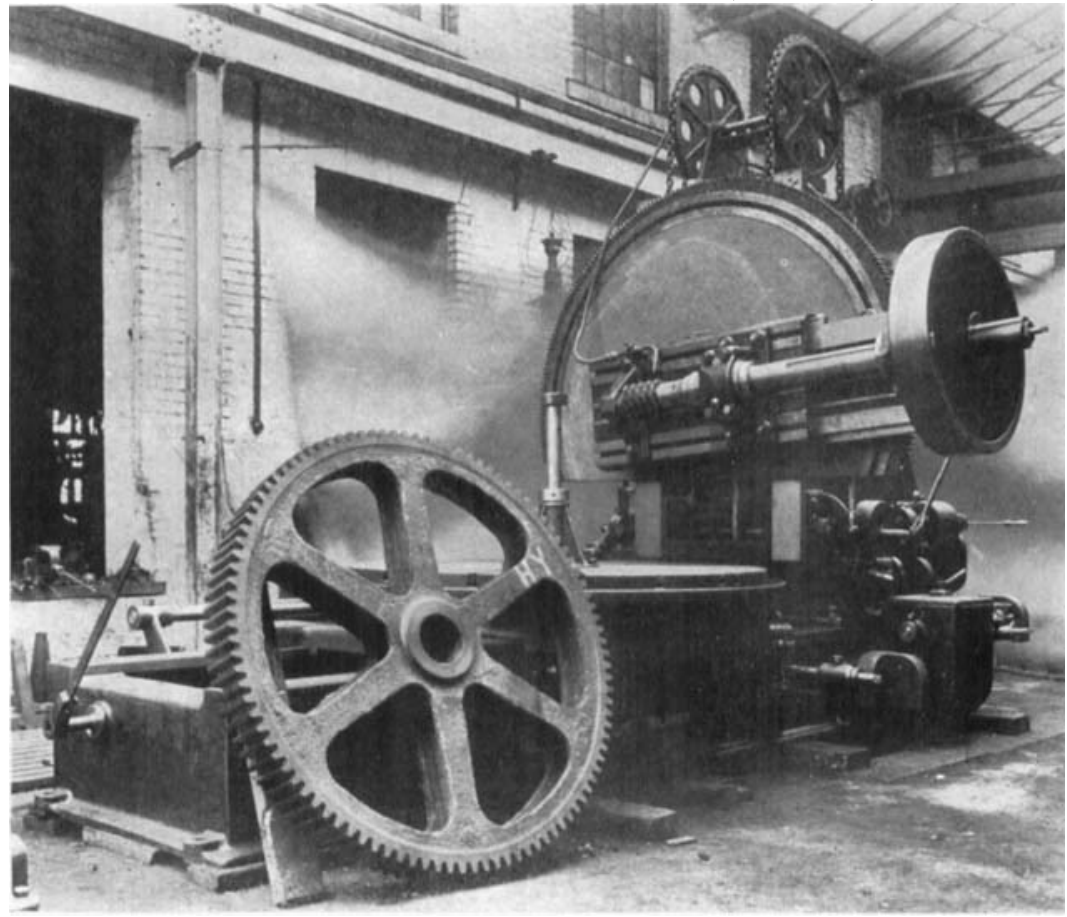

Fig. 25. Gear-Hobbing Machine. (Reinecker.) 1894.

Fig. 26. 32-inch Gear-Hobbing Machine. (See next Plate.) (Humpase, Thompson and Hardy.)

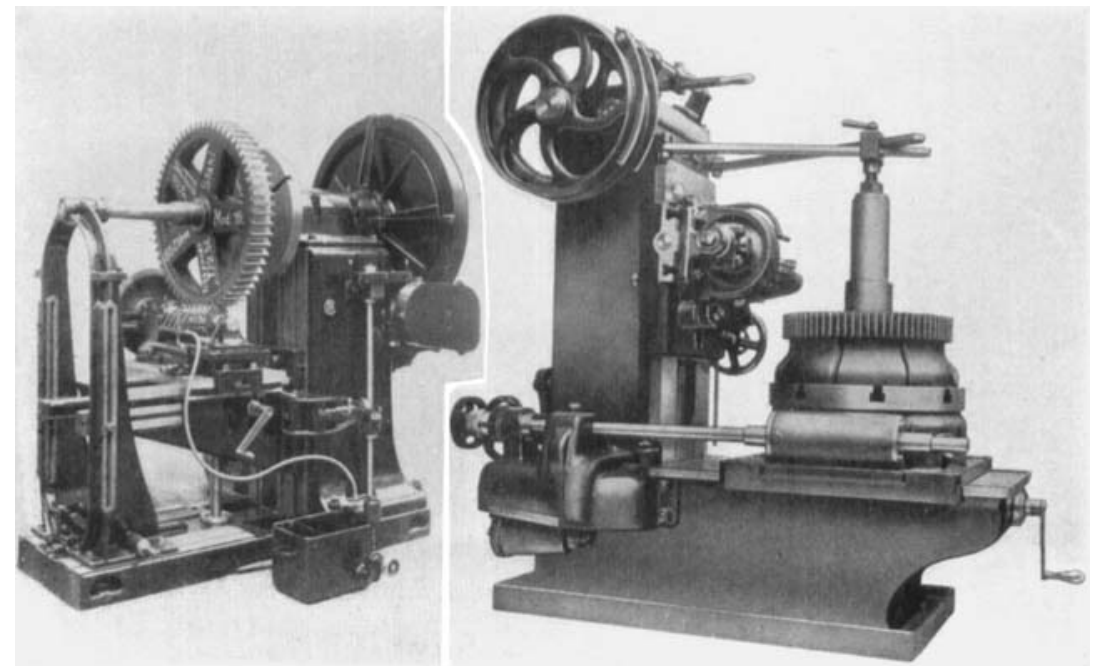

Mechau Downloaded from pme.sagepub.com at UNIV NEBRASKA LIBRARIES on September 5, 2015 
32-inch Gear-Hobbing Machine, Fig. 26.

Fig. 27. Speed Gear and Details.
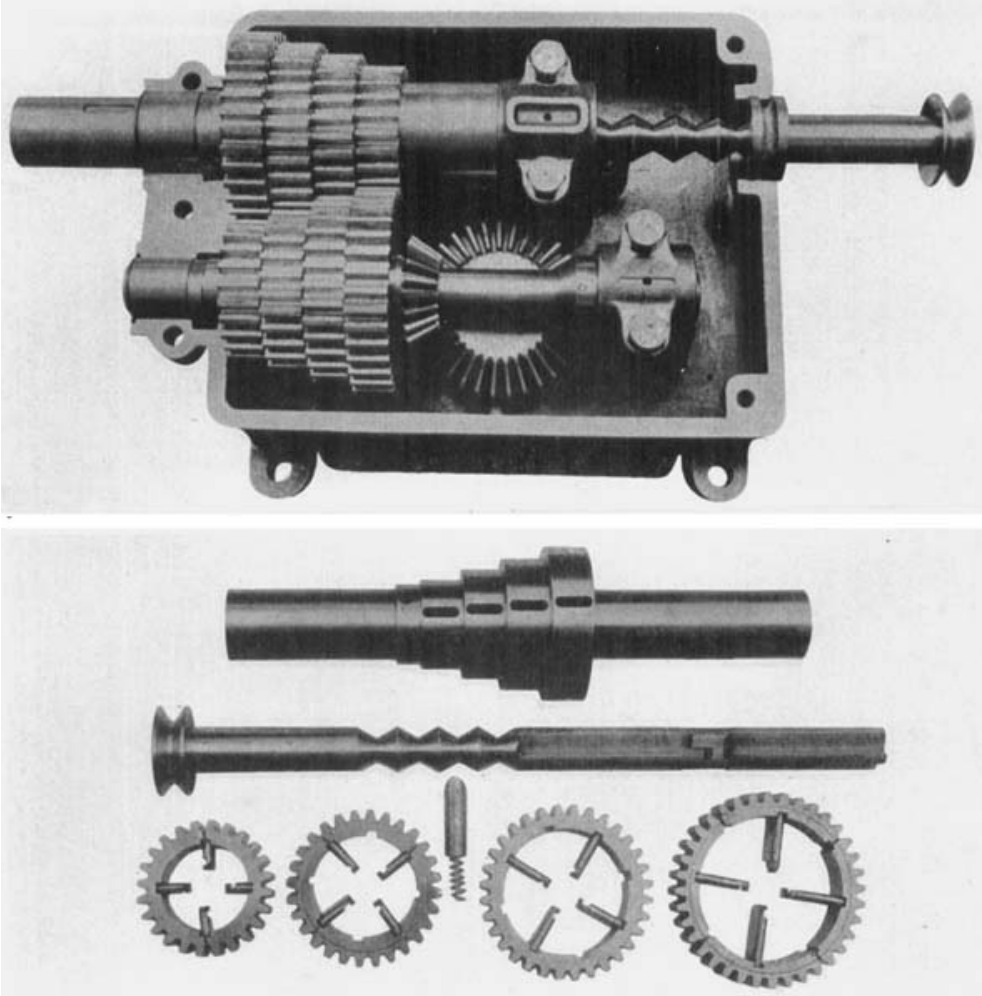

Fig. 29. Feed-Gear.

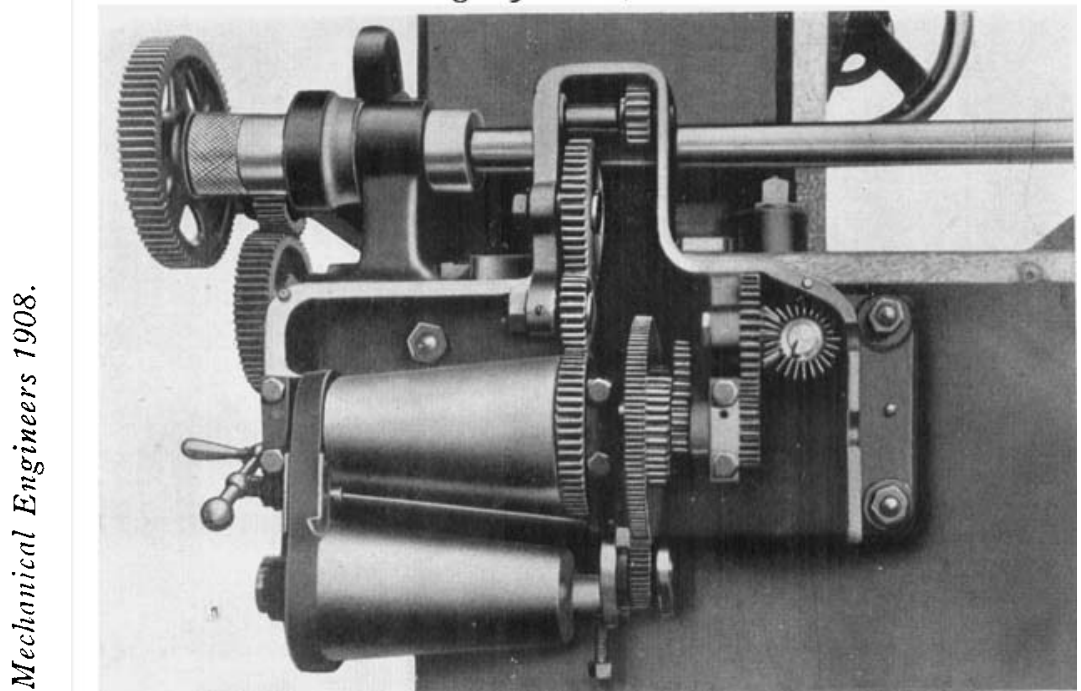

Downloaded from pme.sagepub.com at UNIV NEBRASKA LIBRARIES on September 5, 2015 